\title{
ESTUDO DA VARIABILIDADE E CORRELAÇÕES ENTRE CARACTERES AGRONÔMICOS EM POPULAÇÕES \\ DE Centrosema pubescens Benth
}

\author{
WILSON REIS MONTEIRO \\ Engenheiro-Agrônome
}

Orientador: Dr. Paulo Sodero Martins

\begin{abstract}
Dissertação apresentada à Escola Superior de Agria culłura "Luiz de Queiroz", da Universidade de São Paulo, para obtenção do título de Mestre em Genética e Melhoramento de Plantas.
\end{abstract}

$P|R A C| C A B A$

Estado de São Paulo - Brasil

Abril, 1980 
.ii.

\section{BIOGRAFIA DO AUTOR}

WILSON REIS MONTEIRO, filho de João Monteiro So brinho e Maria José Reis Monteiro, nasceu em Nepomuceno-Minas Gerais, aos 28 dias do mês de setembro de 1951. Iniciou seus estudos médios na cidade natal e concluiu os mesmos na cidade de São Paulo. Em 1973, ingressou na Escola Superior de Agricultura de Lavras, obtendo o diploma de Engenheiro Agrônomo em 18 de dezembro de 1976, na mesma escola. Em margo de 1977, iniciou as suas atividades profissionais, em Lavras, como professor horista na Escola Superior de Agricultura de Lavras (ESAL). Em abril do mesmo ano foi contratado como professor auxiliar de ensino pela Universidade do Amazonas, onde exerceu suas fungões até dezembro de 1977. Em margo de 1978, iniciou - curso de mestrado em "Genética e Melhoramento de Plantas:",na ESALQ/USP. 
.iii.

\author{
Para os meus pais \\ João Monteiro e Maria José \\ MINHA GRATIDAO.
}

\author{
Para os meus irmãos \\ Renato, Maurilo, Eliana e Eliezer \\ MEU OFERECIMENTO
}
Para minha espôsa Iamir
e meus filhos.
Antiōgenes e Wilson In.
MINHA DEDICAÇÃO.




\section{AGRADECIMENTOS}

Expresso meus sinceros agradecimentos a todas as pessoas e instituições que, direta ou indiretamente, colabo raram para a realização do presente trabalho, especialmente:

- Ao Prof. Dr. Paulo Sodero Martins, pela segura orientação e amizade.

- Aos Profs. Dr. Natal Antonio Vello e José Branco de Miranda Filho, pela oportuna orientação na parte estatís tica do presente trabalho.

- Aos Profs. Dr. Randolfo W.S. Custódio e João Rubens Zinsly, pelo apoio e amizade.

- Ao Instituto de Zootecnia de Nova Odessa e Es tação Experimental de Itaguái, pela doação das sementes utilizadas no presente trabalho.

- Ao Prof. Ernesto Paterniani, Chefe do Departa mento de Genética, pelas facilidades concedidas.

- A Comissão Executiva do Plano da Lavoura Cacaueira (CEPLAC), pelas facilidades concedidas.

- Aos Srs. João Bosco dos Santos, Antonio Rezen de Soares e Mauro Nobrega pelas valiosas sugestões. 
- A Srta. Marizinha Anastácio de Oliveira pela revisão e correções efetuadas no manuscrito.

- Ao corpo docente do Departamento de Genética, pela dedicação e ensinamentos.

- Aos colegas do curso que compartilharam de to dos os momentos vividos durante o decorrer do mesmo.

- Aos funcionārios do Instituto de Genética, pe la atenção dispensada.

- À mitha esposa Jamir e meus filhos, pela cons tante comparticipação, principalmente nos momentos mais dificeis.

- Ao Conselho Nacional de Desenvolvimento Científico e Tecnológico (CNPq), pela bolsa de estudos recebida. 


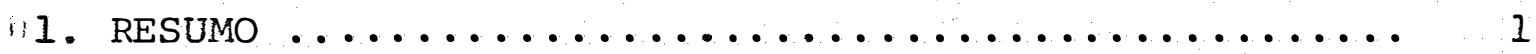

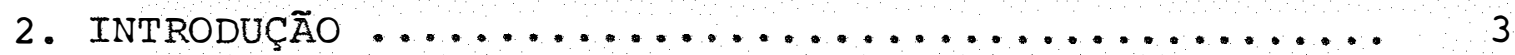

3. REVISÃo DE LITERATURA .......................... 6

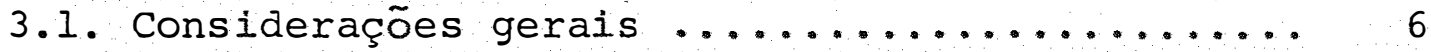

3.2. Estudos sobre o gênero Centrosema (D.C.) Benth 8

3.3. Estudos sobre a espécie Centrosema pubescens

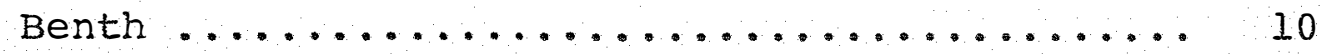

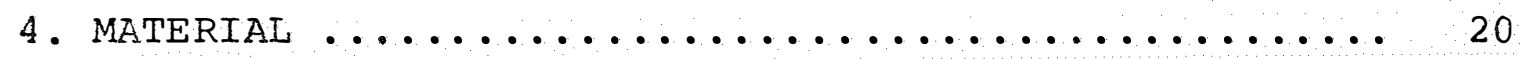

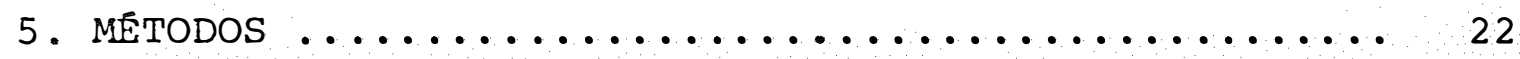

5.1. Preparo das sementes ................... 22

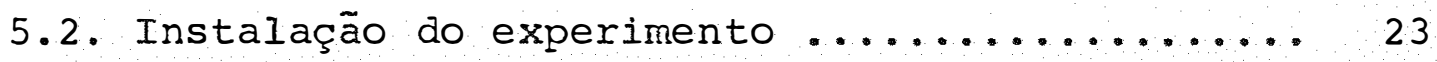

5.3. Tratamento estatístico genético ............. 25

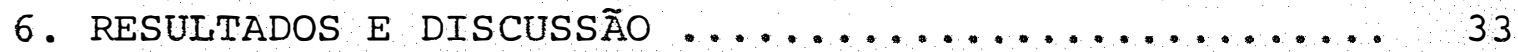

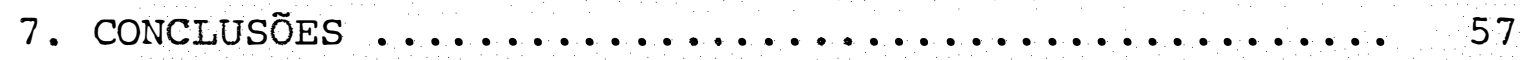

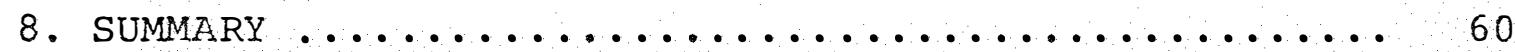

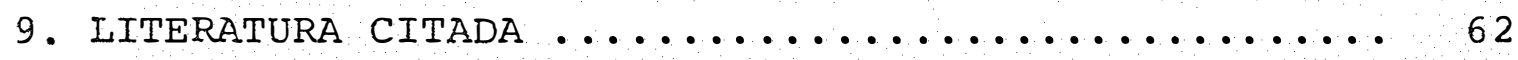


1. RESUMO

Com o objetivo de avaliar, entre 21 populações de Centrosema pubescens Benth, a variabilidade genética para os caracteres, peso da matéria verde, peso da matéria seca, nú mero de ramificações primārias, comprimento da ramificação, pri mária, comprimento médio dos internódios e número de vagens pro duzidas por planta, e também determinar a correlação fenotípica e ambiental entre eles, foi conduzido na cidade de Piracicaba, SP, no ano de 1979, um ensaio numa área pertencente ao Instituto de Genética/ESALQ.

o delineamento experimental empregado foi 0 de blocos casualizados, com seis repetições, 21 tratamentos (popu lações) e seis plantas por parcela.

Pode-se verificar que os caracteres, numero de vagens produzicas por planta, comprimento médio dos internódios, número de ramificações primárias e peso da matéria verde 
apresentaram maior variabilidade genética.

Verificou-se ainda, que a maioria dos caracteres estudados estão bem correlacionados fenotipicamente e que entre alguns deles a correlação ambiental é muito grande.

Uma análise baseada na média geral de cada carā ter, indicou que as populações EEI-35/76, IZ-724, IZ-345, IZ245, IZ-246, IZ-243 e a cultivar Deodoro preencheram melhor os requisitos para uma boa forrageira, por apresentarem desejáveis desenvolvimento vegetativo e produção de vagens. 


\section{INTRODUÇÃO}

A exploração pecuāria no Brasil apoia-se praticamente na produção das pastagens como fonte de alimento, e co mo esta exploração pecuāria é feita pirincipalmente em áreas de cerrado. que se caracterizam pela baixa qualidade forrageira de sua vegetação natural e grande flutuação estacional na oferta de alimento, apresenta produtividade muito baixa por unidade de ārea.

Nos ültimos anos, a exportação de carne assumiu papel de destaque na economia brasileira, sendo que ultimamente tornou-se uma das principais fontes de divisas do orçamento nacional (SERPA, 1974a). Considerando portanto este fato e a tendência do mercado mundial a consumir sempre mais proteinas de origem animal, torna-se necessärio o estabelecimento de um programa de melhoramento de pastagens, que atenda com maior eficiência e rapidez a situação atualmente existente. 
A disponibilidade de forragem verde nas pastagens tropicais e subtropicais, varia muito de uma estação para outra, e de ano para ano, sendo esta uma das causas principais do crescimento lento e irregular dos animais.

A necessidade de aumentar a disponibilidade de proteina vegetal na alimentação dos animais e atenuar o proble ma da disponibilidade de forragem verde durante a estação seca, pode ser superada pela consorciação de gramíneas e leguminosas, nas pastagens. Segundo HYMOWITZ (1971), esta alternativa parece ser a mais prática e econômica, pois além de aumentar o suprimento protéico da dieta animal, fornece através da fixação simbiótica, o nitrogênio necessário ao crescimento das gra mineas.

Existe no Brasil, um número bastante grande de leguminosas forrageiras nativas, que ainda não foram devidamen te exploradas quanto ao seu potencial forrageiro, sendo que a escassez de pesquisas e informações sobre a variabilidade inter e intra-especifica, dificulta muito o trabalho do melhoris ta.

Considerando portanto, o estágio de desenvolvimento das pesquisas na área de melhoramento de forrageiras no Brasil, o valor potencial das leguminosas nativas e a necessidade de se obterem informações básicas sobre a variabilidade natural dessas espécies, procurou-se estudar o comportamento e 
a variabilidade da espécie Centrosema pubescens Benth, uma vez que, esta leguminosa está enquadrada entre as espécies de valor forrageiro e vem apresentando excelente comportamento em diversos tipos de pastagens.

Os principais objetivos deste trabalho foram os seguintes:

a. Estudar a variabilidade genética de alguns caracteres de valor agronômico-forrageiro.

b. Medir a magnitude desta variabilidade.

c. Determinar coeficientes de determinação geno típica, para os caracteres estudados.

d. Determinar a correlação fenotípica entre esses caracteres.

e. Determinar a correlação entre esses caracteres, devido á efeitos ambientais. 
.6

\section{REVISÃO DE LITERATURA}

\subsection{Considerações gerais}

Os dois grupos de plantas de maior importância econômica para a alimentação, em termos de agricultura mundial, são as leguminosas e as gramineas, estando portanto, incluidas aqui as leguminosas de valor forrageiro (WHYTE et alii, 1955).

Na produção pecuária, o fator mais importante com que devemos nos preocupar è a alimentação do rebanho, e o modo mais econômico de atender as exigências alimentares dos animais, é atravès do alimento fornecido pelas pastagens, que são normalmente formadas à base de duas familias de plantas: as leguminosas e as gramineas.

Nas zonas temperadas, o uso de pastagem mista é muito comum. Nas áreas tropicais, até pouco tempo, toda a atenção era dada às gramineas, mas atualmente, tem-se dado ên- 
fase às leguminosas forrageiras, pois è sabido que a introdução das mesmas, ajuda a recuperar as pastagens, aumentando a quantidade e melhorando a qualidade da forragem, além de melhorar a fertilidade do solo. Os efeitos dessa associação têm sido analisados por diversos autores, tanto em regiões tropicais como em regiões temperadas (HORREL e NEWHOUSE, 1965; MONTEIRO, 1977; STOBBS, 1965).

ROCHA E ARONOVICH (1972), baseando-se em resultados de pesquisas em pastagens e nos ensaios agronômicos realizados no Brasil, sugeriram o uso de pastagens mistas, de leguminosas e gramineas, como fator essencial para o desenvolvimento da produção animal.

VASCONCELOS (1972) sugeriu que estudos diversos devam ser conduzidos para verificar, em cada região e até mesmo para cada tipo de solo, a adaptação de determinada legumino sa forrageira, observando as suas necessidades nutricionais e os nutrientes limitantes do seu desenvolvimento.

Em locais como a Flórida e a Austrália, existe um interesse crescente na utilização comercial dessas plantas forrageiras, em consequência do aumento exagerado do custo de fertilizantes nitrogenados. WHYTE et alii (1955), assinalaram que na Austrália meridional, os experimentos em solos podzolizados, deficientes em nitrogênio e fósforo, demonstraram a pos sibilidade de se obterem melhoras rápidas, quando se emprega 
uma combinação adequada de leguminosas herbáceas e adubos.

Segundo JONES et alii (1970), a introdução de leguminosas constitui, provavelmente, o método mais econômico de se adicionar nitrogênio ao sistema solo-planta.

No gênero Centrosema existem vārias espécies que são úteis como plantas forrageiras, apresentando portanto, boas características como tais. Entre essas espécies as que mais se têm destacado e, consequentementè, aquelas que estão sendo mais exploradas devido as suas potencialidades são segundo BOGDAN (1977): Centrosema brasilianum Benth, Centrosema pubescens Benth e Centrosema virginianum Benth.

Alguns estudos de avaliação já foram feitos na espécie $C$. pubescens Benth, com a finalidade de aproveitá-la em pastagens no Brasil (ARONOVICH et alii, 1970).

3.2. Estudos sobre o gēnero Centrosema (D.C.) BENTH

O gênero Centrosema pertence à famîlia Legumino sae, subfamilia Papilionoideae, tribo Phaseolae. E originärio da América do Sul. O gênero contem cerca de 40 a 50 espécies, distribuidas através da América Central, do sul e Caribe (BOGDAN, 1977; CLEMENTS, 1977; TEITZEL e BURT, 1976). As espécies são plantas herbáceas ou sub-arbustivas com hábito de crescimento trepador ou prostrado. A maioria possui folhas compostas, trifoliadas (em algumas espécies com um ou sete folio- 
los), inflorescência axilar, fruto linear do tipo legume, pro duz uma raiz bem desenvolvida e são plantas perenes (ALCÂNTARA E BUFARAH, 1979; BOGDAN, 1977; MONTEIRO, 1977; OTERO, 1961).

Entre as espécies deste gênero as mais conhecidas são as seguintes (BARBOSA=FEVEREIRO, 1977; CORREA, 1926):

1. Centrosema arenarium Benth.

2. Centrosema bifidum Benth.

3. Centrosema brasilianum Benth.

4. Centrosema coreaceum Benth.

5. Centrosema parviflora Benth.

6. Centrosema pascuorum Mart.

7. Centrosema plumiere Benth.

8. Centrosema pubescens Benth.

9. Centrosema rotundifolium Mart.

10. Centrosema venosum Mart.

11. Centrosema vexillatum Benth.

12. Centrosema virginianum Benth.

As espécies 1, 2, 4, 5, 6 e 9 ocorrem no Brasil, porém pouco ou nada se sabe sobre o seu valor forrageiro. As espécies 3, 7, 8, 10, 11 e 12, também ocorrem no Brasil e são consideradas plantas de valor forrageiro.

Muitas dessas espécies, especialmente a C. plumiere Benth., foram introduzidas no Congo, Java, Malásia, Ugan da e no sul da Ásia, sendo cultivadas como cultura de cobertu- 
ra de solo em plantações de citrus, seringueira, dendezeiro, coqueiros e cacaueiros e, além disso, são muito usadas nessas regiões como adubo verde (BOGDAN, 1977; WHYTE et alii, 1955 ; WILSON E LANSBURY; 1958).

A C. brasilianum Benth., assemelha-se à C.pubes cens e è comum no Brasil e nos países vizinhos. Na Austrälia, produziu 15 ton de matéria seca/hectare/ano, mais do que qualquer outra introdução de centrosema, sendo que a maior parte dessa produção foi obtida no período seco (BOGDAN, 1977).

3.3. Estudos sobre a espēcie Centrosema pubescens Benth.

A C. pubescens Benth., possui em suas células somāticas um nümero de cromossomas igual a 20. E uma espécie perene, trepadora ou rastejante, com ramos finos e pubescentes, herbācea, agressiva, possuindo folhas compostas trifoliadas, com forma variando entre eliptica, oblonga, lanceolada-ovalada e eliptica oval, com 1,5 a 7,0 cm de comprimento e 0,6 a 4,5 cm de largura. A inflorescência é do tipo rácimo axilar com flores grandes, tamanhos variados, vistosas, com corolas de co loração variando de branca, rosada a violeta. Os estames são diadelfos e o ovário é séssil. O fruto é seco, linear, de com primento variando de 2,0 a $17,0 \mathrm{~cm}$ e ãeiscente. As sementes são oblongas, de cor havana, vermelha amarronzada e listradas de preto, com 4 a $5 \mathrm{~mm}$ de comprimento para 2 a $3 \mathrm{~mm}$ de largura (FICANNTARA e BUFARAH, I979; BOGDAN, 1977; MATTOS, 1973; WHYTE 
.11 .

et alii, 1955). Quanto ao tipo de reprodução a C. pubescens foi enquadrada no grupo das plantas quase exclusivamente autofecundáveis (HUTTON, 1960).

A espēcie $C$. pubescens Benth., é tambēm conheci da como C. intermedium A. Rich, C. mole Mart., e sendo denominada vulgarmente por Centro, Jitirana e Centrosema no Brasil (ALCÂNTARA et alii, 1977; BARBOSA-FEVEREIRO, 1977; BODGAN, 1977; CORREA, 1926; MATTOS, 1973; OTERO, 1961). Ocorre ; naturalmente na América do Sul, desde as regiões equatoriais até as latitudes $20^{\circ}$ Sul (ALCÂNTARA et ali $i$, 1977; PEDROSA e ROCHA, 1977).

Segundo MATTOS (1973) e ALCÂNTARA $\cdot$ e BUFARAH (1979), a C. pubescens desenvolve-se bem em locais onde a precipitação pluvial méaia anual é superior a $1270 \mathrm{~mm}$ e a tempera tura média anual estiver entre 22 a $30^{\circ} \mathrm{C}$. Embora seja espécie adaptada à regiões de baixa altitude, já foi observada ocorren do em altitudes de 1260 metros no Panamá (TEITZEL e BURT, 1976). Segundo estes autores e também MATTOS (1973), a C.pubescens re siste muito bem às geadas. Embora, esta cause severos danos, a rebrota e a recuperação das plantas são rápidas em stands bem estabelecidos.

o estabelecimento da c. pubescens, é efetuado pela semente e esta espécie é lenta para se estabelecer (6 a 9 meses) e exige boas condições äurante este período. A imper 
meabilidade do tegumento das sementes influi no seu estabeleci mento e normalmente a proporção de sementes impermeáveis é alta, em torno de 60\% (BOGDAN, 1977; TEITZEL e BURT, 1976). Segundo GRAY citado por PHIPPS (1973), a baixa porcentagem de germinação é principalmente atribuida ao revestimento duro da semente, o qual impede a entrada de āgua.

As sementes de $C$. pubescens apresentam hilo levemente colorido. Dois tipos de sementes já foram identificados quanto à presença ou ausência de um contôrno marrom nas margens do hilo (SERPA, 1965). Uma correlação entre a coloração do hilo e a permeabilidade da semente foi constatada e com provada pelo mesmo autor, o qual mostrou ainda, a viabilidade de obtenção de variedades com sementes permeáveis e relatou que, embora o mecanismo da herança deste carāter não seja bem conhecido, a fixação dos caracteres desejáveis pode ser obtida com relativa facilidade.

A Centrosema pubescens se estabelece muito bem em solos áridos e sem fertilizantes, devido ao fato de seu sis tema radicular ser bem desenvolvido e profundo (ALCÂNTARA et arii, 1977).

A C. pubescens tem se destacado como uma forrageira de alta capacidade fixadora de nitrogênio. Ela contribui com cerca de $280 \mathrm{~kg}$ de nitrogênio/hectare/ano para o solo (MONTEIRO, 1977). Em associação comumente usaãa com Cynodon e Plectystachyum, aumentou o conteúdo de nitrogênio da grami.- 
nea de 1,8 para 2,48 (NORRIS, 1972).

Segundo BOGDAN (1977), a C. pubescens é altamen te seletiva no seu requerimento de Rhizobium. Além disso o mesmo autor relatou que, na Nigéria, a nodulação e fixação de nitrogênio foram melhores em solos de $\mathrm{pH}=6,0$ e decresceram com o aumento do valor do $\mathrm{pH}$.

De acordo com WHYTE, MOIR e COOPER, citados por MONTEIRO (1977), o principal problema no manejo de uma pastagem, para obter altas produções e elevado valor nutritivo, parece estar no fornecimento contínuo de quantidades adequadas de nitrogênio. O rendimento das leguminosas forrageiras tropi cais é bastante variável e está intimamente relacionado com a fertilidade do solo.

- macronutriente considerado limitante para o desenvolvimento e estabelecimento da $C$. pubescens é o fósforo. Este elemento influi na produtividade, na nodulação, na fixação de nitrogênio e matéria seca. Numa adubação, de nada adianta fornecer os outros elementos se o fósforo não for incluido na mesma (AIBA, 1963; NEME e NERY, 1965; PEDROSA e ROCHA, 1977; TOSI et alii, 1975; WENER et alii, 1972). O boro e o mo Iibdênio são os micronutrientes mais importantes e aumentam a resposta ao fósforo (BOGDAN, 1977).

A C. pubescens resiste bem à solos com concentrações altas de manganês, em comparação com outras espécies 
de leguminosas forrageiras, e apresenta bom desenvolvimento ra dicular nestes tipos de solos (BOGDAN, 1977; SOUTO e DöBEREINER, 1969) .

BOGDAN (1977) mencionou em sua revisão sobre o gênero Centrosema, que em stand puro, a produção de forragens em C. pubescens varia, e que no Brasil a mesma chega a produzir de 3,0 a 5,0 ton de matéria seca/hectare, dependendo. do conteúdo de $\mathrm{P}$ e K. O mesmo autor relatou, também, que produções maiores têm sido obtidas em Ghana $(7,6$ ton de matéria seca/ha) e na Austrália (acima de 12 ton de matéria seca/ha) para a cultivar Belalto. CARVALHO, citado por VASCONCELOS (1972), relatou produções de 14,1 ton de matéria seca/ha para centrose ma, enquanto que NEME e NERY (1965), encontraram produções de 5,6 ton de matéria seca para a mesma.

O uso de leguminosas forrageiras, consorciadas com gramineas, tem proporcionado aumentos consideráveis na pro dução de carne e leite nas regiões tropicais. Entre estas leguminosas forrageiras a $C$. pubescens tem se destacado como bas tante promissora, para ser utilizada em pastagens consorciadas, por apresentar diversas características favoráveis como: alta produção de matéria seca, boa capacidade de nodulação, baixa exigência nutricional e resistência à seca (MATTOS, 1974).

A C. pubescens é considerada, dentre as leguminosas forrageiras tropicais, uma das que melhor se consorcia 
com as gramíneas mais expressivas dos pastos naturais, bem como, com aquelas que são usadas na formação de pastagens cultivadas. As gramíneas, que com a $C$. pubescens deram as melhores consorciações, foram as seguintes: capim colonião (Panicum maximum), capim jaraguá (Hyparrhenia rufa), capim elefante (Pennisetum purpureum), capim brachiaria (Brachiaria decumbens), capim gordura (Melinis minutiflora), Digitaria decumbens, Brachiaria mutica, Paspalum notartum e outras (ALCÂNTARA et alii, 1977; BOGDAN, 1977; FURTADO et alii, 1977.a, b, c, di NOGALLES, 1955; SERPA, 1974a; ZERPA e VILLALOBOS, 1953).

CARVALHO et alii (1975) realizaram estudos para comparar o estabelecimento de diferentes leguminosas forrageiras tropicais, em consorciação com gramineas, e constataram que a centrosema teve bom comportamento, tendo apresentado no final do experimento, uma proporção de centrosema superior a das gramineas no campo.

Em consorciação com gramineas, a $C$. pubescens normalmente aumenta a produção total de forragem, quando compa rado com o crescimento apenas das gramíneas (BOGDAN, 1977). O mesmo autor relatou em sua revisão, que a inclusão de C. pubes cens, aumentou a produção total de Pennisetum polytachion (India), de 5,4 ton/hectare para 9,3 ton/ha e também de Digitaria decumbens (Flórida), de 5,24 ton/ha para 9,39 ton/ha e aumen tou o conteúdo protéico da forragem de 6,0 para 9,9\%. 
Em pastagens consorciadas de capim pangola com C. pubescens e capim gordura com $C$. pubescens, foi observado um ganho/ha de produto animal bem elevado, usando lotação fixa (ARONOVICH et alii, 1974; SARTINI et alii, 1975).

STOBBS (1965) baseando-se nos resultados de ensaios de gramíneas e gramíneas mais leguminosas, concluiu que a C. pubescens aumentou a produção animal. Aumentos de $280 \mathrm{~kg}$ para $527 \mathrm{~kg}$ de carne/ha/ano foram obtidos pela adição desta le guminosa. O autor constatou também que o maior valor desta le guminosa era durante a estação da seca. Em pastagens consorciadas com Digitaria decumbens mais $C$. pubescens, foi verifica do um ganho de peso vivo de $349 \mathrm{~kg} / \mathrm{ha}$ para $410 \mathrm{~kg} / \mathrm{ha}$ (BOGDAN, 1977). Em pasto misto de gramíneas e centrosema, com uma carga animal de 2,4 cabeças/ha, foi obtido um ganho de peso vivo de $172,1 \mathrm{~kg} / \mathrm{ha}$ (MATTOS et alii, 1978). Segundo VASCONCELOS (1972), a qualidade da forragem nas pastagens, è evidenciada em termos de capacidade de ganho de peso pelos animais.

$$
\text { JONES et alii (1970), PEDREIRA et alii }
$$

e TEITZEL e BURT (1976), também verificaram ganho de peso vivo elevado em pastagens consorciadas de gramíneas mais $C$. pubes cens. Verificaram ainda que estes pastos suportam em média 1,6 a 2,4 cabeças/ha, o ano todo.

A forragem de C. pubescens contém de 11 a $24 \%$ de conteūdo protéico. Seus ramos são finos e não lignificados 
e seu valor nutritivo é alto. Embora palatável, é menos prefe rida do que a graminea, principalmente durante o período úmido. o gado tem que ser treinado ou induzido a usar a forragem de c. pubescens em sua alimentação, antes de serem ministradas grandes quantidades para serem consumidas pelo mesmo. A forra gem contém alguns oxalatos na sua composição (BOGDAN, 1977).

KANNEGIETER (1965), encontrou 22,5\% de proteina bruta na centrosema e ANDREW e ROBINS (1969), encontraram 22,62 e 16,94\% de proteína bruta para centrosema e soja perene, respectivamente. Esses resultados concordam com os de CHOU et alii (1977), MATTOS et alii (1978), NEME e NERY (1965), PEIXOTO et alii (1965) e CARVALHO, citado por VASCONCELOS (1972), que encontraram, sempre, maiores níveis protéicos para a c. pu bescens, quando comparadas com outras leguminosas forrageiras.

REYS (1955), fez um estudo sobre a digestibilidade da $C$. pubescens e kudzu tropical e constatou que a centro sema apresentou mais proteina digestível do que o kudzu tropical, embora este tenha apresentado mais nutrientes digestíveis totais. VASCONCELOS (1972), citou que, num ensaio de digestibilidade "in vitro" da matéria seca, realizado por SILVA et alii, usando rumem de carneiros fistulados e envolvendo soja perene e centrosema em 3 estágios de vegetação, foi encontrado, respectivamente, $78,28,68,51$ e $62,92 \%$ de digestibilidade da matéria seca para soja perene e $75,41,64,84$ e 61,62\% para a centrosema. 
A palabilidade da $C$. pubescens é boa (MATTOS, 1973). Este caráter é determinado pelo grau de atração dos animais pelas forragens e essa é de grande importância na determinação da quantidade de alimento consumido e na taxa de produção animal.

SOUTO et alii (1975) e PETIT (1968) utilizaram técnicas distintas para avaliar a palatabilidade da $C$. pubescens. Os autores concluiram que a centrosema è uma leguminosa forrageira de boa palatabilidade, comparada com outras espécies.

A produção de sementes em $C$. pubescens é relati vamente boa. A colheita é feita de 6 a 12 meses após a semeadura e esta é, muitas vezes, dificultada devido ao prolongado florescimento. Na Austrália, são citadas produções de 300 a $600 \mathrm{~kg} / \mathrm{ha}$, enquanto que para as nossas condições são de 300 a $450 \mathrm{~kg}$ de semente/ha. Em I kg de sementes de centrosema, existe em mēdia de 33.000 a 40.000 sementes (BOGDAN, 1977).

SERPA (1974a), realizou um estudo com o objetivo de conhecer a variabilidade de alguns fatores que influenciam a produção de sementes em $C$. pubescens. Vários caracte res foram estudados na ocasião, ou sejam: nümero de vagens pro duzidas por planta, número de sementes por vagem, período de maturação das vagens, peso seco de 100 sementes a $105^{\circ} \mathrm{C}$, deiscência das vagens, pragas e doenças. O autor concluiu que a 
grande variabilidade dos caracteres estudados, estabelece ampla possibilidade de êxito, no sentido de selecionar linhagens com boa produção de sementes, e que o nümero de vagens produzi das por planta foi o caráter mais correlacionado com a produção de sementes $(r=0,92)$.

Com relação ao melhoramento, poucos trabalhos existem com essa espécie. SERPA (1974b e 1977) utilizou a téc nica da hibridação interespecífica, como meio alternativo de conseguir leguminosas forrageiras melhoradas. A espécie Cen trosema virginianum apresenta grande capacidade de enraizamento nas ramificações e baixa produção de sementes. Na C.pubescens ocorre a situação inversa. A idéia do cruzamento entre as duas espécies foi a de se obter um genótipo capaz de corrigir as deficiências dessas espécies. O autor obteve, portanto, os híbridos $C$. pubescens $x C$. virginianum e o seus recípro $\cos e$, observou que no $F_{I}$, determinados caracteres como, cor das flores de $C$. pubescens, fixação de $\mathrm{N}_{2}$ atmosférico, enraiza mento abundante, boa produção de sementes, velocidade inicial de crescimento, desenvolvimento vegetativo intenso e tolerância à seca, comportaram como caracteres dominantes. Para uma série de outros caracteres os híbridos interespecíficos obtidos mostraram nítida superioridade em relação à cultivar teste munha de C. pubescens ( $\mathrm{CV}$. Deodoro). 


\section{MATERIAL}

O material utilizado no presente trabalho, cons tou de 21 populações de $C$. pubescens Benth. Cada população re presentou um tratamento experimental no campo de ensaio.

A relação das populações, número de tratamento experimental, número de classificação e a procedência, é a seguinte:

\begin{tabular}{cll}
\hline $\begin{array}{c}\text { Nümero do } \\
\text { tratamento }\end{array}$ & $\begin{array}{c}\text { Número de } \\
\text { classificação }\end{array}$ & \multicolumn{1}{c}{ Procedència } \\
\hline 1 & EEI-129/73a/ & Est. Exper. de Itaguai - RJ \\
2 & IZ-246 $\underline{\text { b/ }}$ & IRI-1346, IRI-Matão - SP. \\
3 & IZ-248 & IPEACS-7/69 \\
4 & IZ-237 & IRI-0022, IRI-Matão - SP. \\
5 & IZ-777 & IPEACS \\
6 & EEI-35/76 & Est. Exper. de Itaguai - RJ
\end{tabular}


- continuação -

Número do tratamento
Número de
classificação

IZ-724

IZ -239

IZ -247

IZ -235

IZ -243

IZ -238

EEI $-4 / 75$

EEI $-26 / 76$

IZ -345

CV. Deodoro

IZ -242

EEI $6 / 66$

IZ -240

IZ-24I

IZ -245
Procedência

IZ, Nova Odessa, SP

IRI-1235, IRI-Matão - SP:

IRI-1332, IRI-Matão - SP

IZ, Nova Odessa, SP

IPEACS-5-1/64

IRI-0234, IRI-Matão - SP

Est. Exper. de Itaguaí, - RJ

Est. Exper. de Itaguai - RJ

IZ, Nova Odessa, SP

Est. Exper. de Itaguaí - RJ

IPEACS $-5-3 / 64$

Est. Exper. de Itaguaí - RJ

IRI-0019, IRI-Matão, SP

IPEACS $-4-2 / 64$

IRI-0234-IRI-Matão， SP

a/ $\mathrm{EEI}=$ Estação Experimental de Intaguai, RJ.

b/ IZ = Instituto de Zootecnia, SP. 
5. METODOS

\subsection{Preparo das sementes e semeadura}

\section{a. Preparo das sementes}

A impermeabilidade do tegumento da semente, impede a entrada de água, dificultando assim sua germinação. Em virtude deste fato, as sementes foram escarificadas, porque es te tratamento dā melhores resultados na germinação (SERPA, 1965). A escarificação foi efetuada com a utilização de uma lixa fina, e sobre esta as sementes foram pressionadas levemen te.

b. Semeadura

As sementes foram semeadas em caixas de plástico, em 23.01.1979 e 04.02.1979, e conservadas em casa de vegetação atē 14.02.1979 e 21.02.1979, respectivamente, quando fo- 
ram repicadas para copos de plástico de $200 \mathrm{ml}$. Permaneceram ainda na casa de vegetação até 14.03.1979, quando foram levadas para campo experimental. Portanto, o período entre a semeadura e o plantio no campo correspondeu em média 45 dias.

\subsection{Instalação do experimento}

As plantas foram transplantadas para o campo em 14.03.1979, tendo sido plantadas no espaçamento de $2,0 \cdots \mathrm{x} 2,0$ $\mathrm{m}$, ou seja, cada planta ocupando uma ärea de $4 \mathrm{~m}^{2}$. Foi feita adubação na cova com 200 gramas de superfosfato simples.

o delineamento experimental utilizado foi o de blocos casualizados, com seis repetições e 21 tratamentos (populações) - Cada parcela foi formada por 6 plantas, ocupando uma área de $24 \mathrm{~m}^{2}$. A ärea experimental total foi $3268 \mathrm{~m}^{2}$. Pọ teriormente, em 26.10.1979 foram cortadas as plantas das posições 4, 5 e 6 de cada parcela, com a finalidade de avaliar os caracteres, peso da matēria verde, peso da matēria seca, nūmero de ramificações primārias. As plantas de posições 1, 2 e 3 fô ram mantidas para as avaliações de comprimento da ramificação primāria, comprimento médio dos internódios e número de vagens.

O período experimental estendeu-se da data do plantio no campo (14.03.1979), até a data da coleta dos últimos dados, em 20.12.1979. Neste período, foram avaliados os 
seguintes caracteres:

a. Peso da matéria verde em quilograma (X)

Este caráter foi avaliado após o corte realizado a $15 \mathrm{~cm}$ do nível do solo, em 26.10.1979, sendo cada planta pesada individualmente. As três plantas de cada parcela utili zadas para corte, foram as mencionadas anteriormente.

b. Peso da matéria seca em quilograma (Y)

Para a avaliação deste carāter, foi tomada uma amostra de $0,277 \mathrm{~kg}$ (meia libra) da parte aérea de cada planta. Essas amostras foram colocadas em saquinhos de papel e levadas para as estufas de circulação contínua, para secagem, à temperatura de $70^{\circ} \mathrm{C}$, durante 85 horas.

c. Nūmero de ramificações primārias (Z)

Após o corte, foi contado em cada planta indiví dual, o número de ramificações primárias.

d. comprimento mēdio dos internōdios em metros (Q)

As medidas, para a avaliação deste caráter, foram realizadas em uma ramificação primária, tomada ao acaso na planta. Foram medidos todos os internódios desta ramificação 
e obtida uma média. Este carāter foi avaliado nas plantas de posições 1,2 e 3 de cada parcela.
e. Comprimento da ramificação primāria em me- $\operatorname{tros}(P)$

Este carāter, também foi obtido através da medi da de uma ramificação primāria tomada ao acaso, em cada planta situada nas posições 1,2 e 3 de cada parcela.

f. Nümero de vagens produzidas por planta $(R)$

O nümero de vagens produzidas por planta foi ob tido de plantas manalmente os frutos maduros de cada planta. A avaliação deste caráter foi feita nas plantas de posições 1, 2 e 3 de cada parcela.

5.3. Tratamento estatístico-genētico

a. Anālise de variāncia

As anālises de variância obedeceram ao delineamento em blocos ao acaso. Para todos os caracteres a análise da variância foi feita baseada em médias de parcelas. As espe ranças matemáticas dos quadrados médios equivalem àquelas de um modelo matemático misto (STEEL e TORRIE, 1960). O modelo matemático usado foi o seguinte: 


$$
\begin{aligned}
& Y_{i j}=m+p_{i}+b_{j}+e_{i j^{\prime}} \quad \text { onde: } \\
& Y_{i j}=\text { representa uma observação fenotípica, na } \\
& \text { população i, na repetição j: } \\
& \text { m = média geral do carāter; } \\
& \mathrm{p}_{i}=\text { efeito genético da população } i \text {, com } i= \\
& 1,2, \ldots . \text { P (populações). Este efeito foi } \\
& \text { considerado fixo; } \\
& b_{j}=\text { efeito ambiental da repetição } j, \operatorname{com} j= \\
& 1,2, \ldots R \text { (repetições). Efeito conside } \\
& \text { rado aleatório; } \\
& e_{i j}=\text { erro experimental da parcela contendo } \\
& \text { plantas da população i, na repetição j• } \\
& \text { Efeito aleatório. }
\end{aligned}
$$

Todos os caracteres foram analisados por meio desta metodologia. O carāter número de vagens produzidas por planta foi transformado para $\log (x+1)$, a fim de se obter uma distribuição mais próxima da normal, a qual se faz necessā ria para a aplicação adequada dos teste de hipótese (STEEL e TORRIE, 1960).

A análise da variância para os caracteres obser vados, foi feita de acordo com o seguinte esquema apresentado no Quadro 1 (KEMPTHORNE; 1973). 
Quadro 1. Esquema da anālise da variância.

\begin{tabular}{lcccc}
\hline Fontesde variação & GL & $Q M$ & $F$ & $E(Q M)$ \\
\hline Repetições & $(R-1)$ & $Q_{3}$ & $Q_{3} / Q_{1}$ & $\sigma^{2}+P_{r}^{2}$ \\
Populações & $(P-1)$ & $Q_{2}$ & $Q_{2} / Q_{1}$ & $\sigma^{2}+R V_{p}$ \\
Erro & $(R-1)(P-1)$ & $Q_{1}$ & & $\sigma^{2}$ \\
\hline Total & $\mathrm{RR}-1$ & & & \\
\hline
\end{tabular}

sendo:

$$
\begin{aligned}
\mathrm{V}_{\mathrm{p}}= & \text { componente quadrático devido as diferenças } \\
& \text { genēticas entre populações; } \\
\sigma_{r}^{2}= & \text { variância ambiental entre repetições; } \\
\sigma^{2}= & \text { variância do erro experimental entre parce } \\
& \text { las. }
\end{aligned}
$$

A partir da anālise da variância para cada cará ter, estimaram-se os componentes da variância da seguinte maneira:

$$
\hat{v}_{\mathrm{p}}=\frac{\mathrm{Q}_{2}-\mathrm{Q}_{1}}{\mathrm{R}} \quad \hat{\sigma}^{2}=\mathrm{Q}_{1}
$$

A estimativa do componente $\mathrm{V}_{\mathrm{p}}$ é válida apenas para as 21 populações estudadas.

Utilizou-se neste trabalho um processo prático, proposto por KEMPTHORNE (1957), para facilitar o cálculo dos produtos médios nas análises da covariância. Este processo con 
siste na análise da variância de $U$, sendo que $U$ representa a soma das observações de um caráter $M$ com as observações de um carater N. Os produtos médios foram determinados da maneira apresentada no Quadro 2 .

Quadro 2. Esquema para obtenção dos Produtos médios.

Fontes de variação $\quad$ P.M.

Repetição

Populações

Erro

$$
\begin{aligned}
& \mathrm{PM}_{3}=1 / 2\left[\mathrm{~B}_{\mathrm{U}}-\mathrm{B}_{\mathrm{M}}-\mathrm{B}_{\mathrm{N}}\right] \\
& \mathrm{PM}_{2}=1 / 2\left[\mathrm{P}_{\mathrm{U}}-\mathrm{P}_{\mathrm{M}}-\mathrm{P}_{\mathrm{N}}\right] \\
& \mathrm{PM}_{1}=1 / 2\left[\mathrm{E}_{\mathrm{U}}-\mathrm{E}_{\mathrm{M}}-\mathrm{E}_{\mathrm{N}}\right]
\end{aligned}
$$

Onde, B, P e E representam os quadrados médios das respectivas fontes de variação: repetições, populações e erro.

O esquema usado para a análise da covariância, foi o proposto por KEMPTHORNE (1973), representado no Quadro 3. 
Quadro 3. Esquema da análise de covariância usada no presente trabalho.

\begin{tabular}{lrll}
\hline Fonte de variação & GL & PM & E (PM) \\
\hline Repetições & $(R-1)$ & $\mathrm{PM}_{3}$ & Cov $+\mathrm{P} \operatorname{Cov}_{\mathrm{r}}$ \\
Populações & $(\mathrm{P}-1)$ & $\mathrm{PM}_{2}$ & $\mathrm{Cov}+\mathrm{R} \operatorname{Cov}_{\mathrm{P}}$ \\
Erro & $(\mathrm{R}-1)(\mathrm{P}-1) \mathrm{PM}_{1}$ & $\mathrm{Cov}$ \\
\hline
\end{tabular}

onde:

$$
\begin{aligned}
\operatorname{Cov}_{p}= & \text { covariância genética entre populações ao } \\
& \text { nível de médias de parcelas; } \\
\operatorname{Cov}= & \text { covariância do erro experimental. }
\end{aligned}
$$

A partir da análise da covariância, entre os ca racteres estudados, estimaram-se os componentes dos produtos médios da seguinte maneira:

$$
\hat{\operatorname{Cov}}_{\mathrm{p}}=\frac{\mathrm{PM}_{2}-\mathrm{PM}_{1}}{\mathrm{R}} \quad \text { Côv }=\mathrm{PM}_{1}
$$

As covariâncias e variâncias fenotípicas foram estimadas através das análises da covariância e variância, res pectivamente.

Os coeficientes de correlação entre caracteres foram determinados através da fórmula (FALCONER, 1964):

$$
r_{x y}=\frac{\operatorname{Cov}(x, y)}{\sigma_{x} \cdot \sigma_{y}}
$$


Com o auxílio desta fórmula tornou-se possivel determinar as correlações fenotípicas entre os caracteres, bem como as correlações devido a efeitos ambientais entre os mesmos, da seguinte maneira:

$$
\begin{aligned}
& \text { a) } \quad r_{F_{X Y}}=\frac{\operatorname{Cov}_{F}(x, y)}{\sigma_{F_{X}} \cdot \sigma_{F}} \quad \text { sendo: } \\
& { }_{F_{X Y}}=\text { coeficiente de correlação fenotípica en- } \\
& \operatorname{Cov}_{F}(x, y)=\text { covariância fenotipica entre dois carac- } \\
& \text { teres }=\operatorname{cov}_{p}+\operatorname{cov} ; \\
& \sigma_{F_{X}} \text { e } \sigma_{F_{Y}}=\text { desvio fenotípico do caráter } \mathrm{x} \text { e } \mathrm{y} \text {, res- } \\
& \text { pectivamente. } \sigma_{F_{X}}^{2}=V_{\mathrm{P}_{\mathrm{X}}}+\sigma_{\mathrm{X}}^{2} \text {. }
\end{aligned}
$$

Foi testada a significância de todos os coefi cientes de correlação fenotípica pelo teste $t$, com $n-2$ graus de liberdade, nos niveis de 5 e $1 \%$ de probabilidade. Em segui da testou-se cada coeficiente contra o outro, com o auxílio das tabelas de $Z(r)$ e de $t$, com infinitos graus de liberdade $e$ n igual a 126 observações (STEEL e TORRIE, 1960).

$$
\text { b) } \begin{aligned}
r_{E}(x, y)= & \frac{\operatorname{Cov}_{(x, y)}}{\sigma_{x} \cdot \sigma_{y}} \\
r_{E, y} & \text { coeficiente de correlação entre carac } \\
& \text { teres, devido a efeitos ambientais; } \\
\operatorname{Cov}_{(x, y)=} & \text { covariância ambiental entre caracte- } \\
& \text { res; }
\end{aligned}
$$



$\sigma_{x}$ e $\sigma_{y}=$ desvio ambiental do carāter $x$ e $y, r e \underline{s}$ pectivamente.

Com relação ao coeficiente de variação, foram feitas as seguintes determinações:

$$
\begin{aligned}
& \mathrm{CV} \%=\frac{\mathrm{s}}{\overline{\mathrm{X}}} \cdot 100 \\
& \mathrm{CV} \%=\frac{\mathrm{s} \mathrm{p}}{\overline{\mathrm{x}}} \cdot 100 \\
& I^{\prime}=\frac{\mathrm{CV}_{\mathrm{g}}^{\circ}}{\mathrm{CV} \%}
\end{aligned}
$$

onde:

$$
\begin{aligned}
& C V \frac{o}{0}=\text { coeficiente de variação experimental; } \\
& \mathrm{CV}_{\mathrm{g}} \frac{\circ}{\circ}=\text { coeficiente de variação genētico entre } \\
& \text { as populações (válido apenas para as } \\
& \text { populações em estudo); } \\
& \text { s = desvio padrão ambiental. } \\
& \mathrm{s}=\sqrt{\mathrm{QM} \cdot \mathrm{erro}} \text {; } \\
& \mathrm{s}_{\mathrm{p}}=\text { desvio padrão genētico entre populações. } \\
& \mathrm{s}_{\mathrm{p}}=\sqrt{\mathrm{V}_{\mathrm{p}}} \\
& \overline{\mathrm{X}}=\text { mêdia geral do caráter; } \\
& \text { I' = indice que indica a variabilidade genéti } \\
& \text { ca de um caráter, em função da variabili } \\
& \text { dade ambiental (VENCOVSKY, 1978). }
\end{aligned}
$$

Para cada carāter estudado, estimou-se um coefi 
ciente de determinação genotípica ( $\left.H^{\prime}\right)$. Este coeficiente se assemelha bastante com $\circ$ coeficiente de herdabilidade, diferin do deste devido ao fato das populações representarem um efeito fixo, segundo o modelo de análise adotado. Este coeficiente (H'), é válido apenas para as populações estudadas neste trabalho e foi determinado da seguinte maneira (CESNICK, 1972):

$$
\begin{aligned}
& H^{\prime}=\frac{V_{P}}{\hat{\sigma}_{\bar{F}}^{2}} \quad \text { onde: }
\end{aligned}
$$

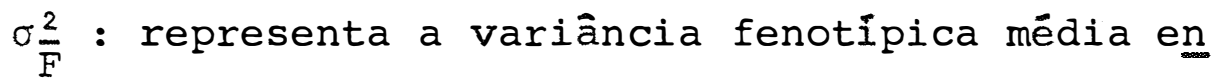

$$
\begin{aligned}
& \text { tre populações. } \\
& \hat{\sigma} \frac{2}{F}=\frac{Q_{2}}{R}
\end{aligned}
$$


Para evitar repetir o nome dos caracteres estudados no decorrer da discussão, adotou-se uma simbologia para designar os mesmos. No Quadro 4, encontra-se a relação dos ca racteres estudados e a simbologia correspondente a cada um deles.

Quadro 4. Relação dos caracteres estudados em C. pubescens, com a respectiva simbologia.

Peso da matéria verde $(\mathrm{kg})$

Peso da matéria seca (kg)

Número de ramificações primārias

Comprimento da ramificação primária (m) 
Os quadrados médios obtidos para os seis caracteres em estudo, acham-se apresentados na Tabela 1. Observa-se nesta tabela que, para todos os caracteres analisados, hou ve alta significância para o efeito de populações, ao nível de l음 de probabilidade, o que indica a existência de considerável variação entre as populações, devido a efeitos genéticos.

Tabela 1. Resumo das análises da variância dos caracteres peso da matéria verde (X), peso da matéria seca (Y), nüme ro de ramificações primārias (Z), comprimento da ramificação primária (P), comprimento médio dos internódios (Q) e nümero de vagens por planta (R) estudados em $C$. pubescens.

\begin{tabular}{lcccc}
\hline Fontes de variação & GL & \multicolumn{3}{c}{ Quadrados médios } \\
\cline { 3 - 5 } & & $\mathrm{X}(\mathrm{kg})$ & $\mathrm{Y}(\mathrm{kg})$ & $\mathrm{Z}(\mathrm{unid})$ \\
\hline Repetições & 5 & 0,1087 & 0,0115 & 17,7214 \\
Populações & 20 & $0,3239 * *$ & $0,0249 * *$ & $67,5218 * *$ \\
Erro exper. & 100 & 0,1255 & 0,0106 & 22,1500 \\
\hline
\end{tabular}

Fontes de variação

GI

Quadrados médios

\begin{tabular}{llll}
\hline$P(m)$ & $Q(m)$ & $R$ & (Unid) \\
\hline
\end{tabular}

Repetições

5

0,0598

0,000076

0,2799

Populações

20

$0,1270 * \star$

$0,000401 * *$

1,3181 *

Erro exper.

100

0.0607

0,000103

0,2092

** significância ao nível de $1 \%$ de probabilidade. 
Na Tabela 2, encontram-se apresentados os coefi cientes de variação experimental (CV), determinados para os seis caracteres em estudo.

Tabela 2. Coeficientes de variação experimental (CVo) dos caracteres analisados, em $C$. pubescens.

Caracteres

$C V$ 웅

Peso da mâtéria verde (kg)

30,711

Peso da matéria seca (kg)

31,466

Número de ramificações primārias

19,803

Comprimento da ramificação primārìa (m)

11,687

Comprimento médio dos internódios (m)

8,840

Número de vagens prod. por planta

40,062

Pode-se verificar que os coeficientes de variação experimental, apresentaram-se maior para alguns caracteres e menor para outros. Isto mostra que, alguns destes caracteres são mais influenciados por fatores ambientais do que outros.

Os caracteres que apresentaram coeficientes de variação mais elevados, como número de vagens produzidas por planta, peso da matéria verde, peso da matéria seca e número de ramificações primārias devem possuir, provavelmente, um con trole poligênico, porque em geral, são mais influenciados pelo 
ambiente.

Observando a magnitude destes coeficientes, pode-se perceber que houve uma boa precisão experimental, durante a coleta e condução do ensaio, considerando a provāvel natu reza poligênica destes caracteres.

Considerando a carência de estudos em relação aos caracteres analisados, neste trabalho, procurou-se isolar para cada carāter, o componente quadrātico devido as diferenças genéticas entre populações $\left(\mathrm{V}_{\mathrm{p}}\right)$ e o da variância do erro experimental $\left(\sigma^{2}\right)$, visando dar uma orientação para futuros estudos.

Para cada caráter foi determinada a variância fenotipica através da soma do componente quadrático devido as diferenças genéticas entre populações mais o componente da variância do erro experimental. Na Tabela 3, são apresentados os componentes da variância $v_{p}$ e $\sigma^{2}$ e a variância fenotípica, para cada carāter analisado. 


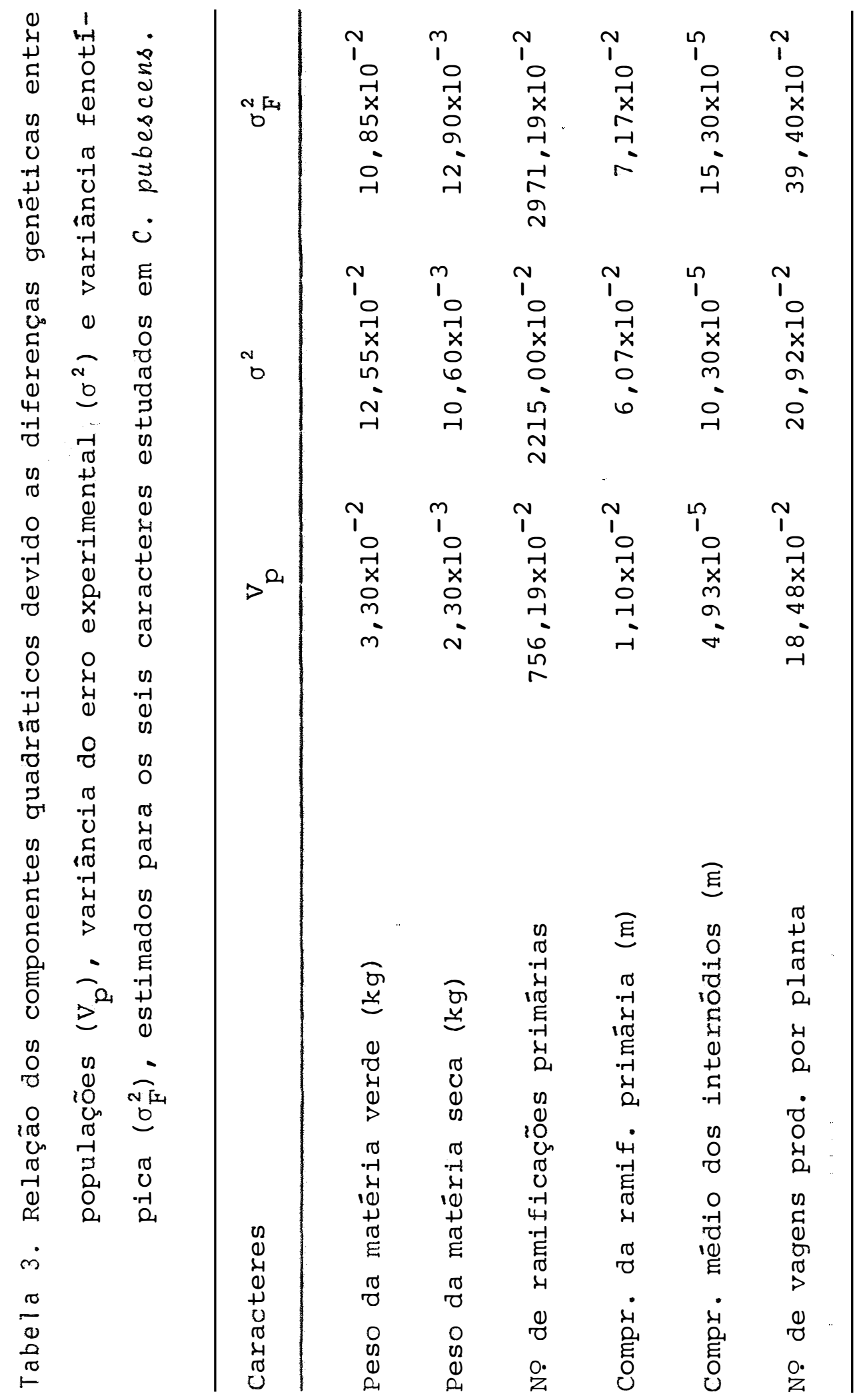


Para comparar a magnitude da variação genética e do erro experimental em cada caráter, procurou-se expressar - valor desses componentes em porcentagem da variância fenotípica. Este procedimento permite dar uma boa orientação, sobre - comportamento de cada carāter. Os dois componentes expressos em porcentagem da variância fenotípica são apresentados na Tabela 4.

Tabela 4. Componente quadrātico devido as diferenças genéticas entre populações $\left(V_{p}\right)$ e variância ambiental $\left(\sigma^{2}\right)$, ex pressos em porcentagem da variância fenotípica, para os seis caracteres analisados em C. pubescens.

\begin{tabular}{lcc} 
Caracteres & $\mathrm{V}_{\mathrm{p}}$ & $\sigma^{2}$ \\
\hline Peso da matéria verde (kg) & $20,82 \%$ & $79,18 \%$ \\
Peso da matéria seca (kg) & $17,83 \%$ & $82,17 \%$ \\
No de ramificaçōes primārias & $25,45 \%$ & $74,55 \%$ \\
Compr. da ramif. primāria (m) & $15,34 \%$ & $84,66 \%$ \\
Compr. médio dos internódios (m) & $34,48 \%$ & $67,32 \%$ \\
No de vagens prod. por planta & $46,90 \%$ & $53,10 \%$
\end{tabular}

De acordo com os resultados aprisentados na Tabela 4, pode-se verificar que existe maior variação genética para os caracteres, número de vagens produzidas por planta,com primento médio dos internōdios, nümero de ramificações primá- 
rias e peso da matéria verde. Esta informação é muito valiosa para futuros trabalhos de melhoramento, pois, com a grande variabilidade genética apresentada por esses caracteres e consequentemente menor influência ambiental em comparação com os ou tros caracteres, métodos de seleção mais simples podem ser aplicados, com grande possibilidade de obtenção de sucesso.

Para todos os caracteres estudados foi determinado um coeficiente de variação genético. Este coeficiente serviu como instrumento para medir a magnitude da variação genética de cada caráter. Estes coeficientes são apresentados na Tabela 5 .

Tabela 5. Relação dos coeficientes de variação genética ( $\mathrm{CV}_{\mathrm{g}} \%$ ) para os seis caracteres estudados em $C$. pubescens.

Caracteres

$\mathrm{CV}_{\mathrm{g}} \mathrm{8}$

Peso da matéria verde ( $\mathrm{kg}$ )

16,118

Peso da matéria seca (kg)

14,666

No de ramificações primárias

11,571

Compr. da ramif. primária (m)

4,975

Compr. médio dos internödios (m)

6,141

No de vagens prod. por planta

33,676

Através da relação entre o coeficiente de varia ção genético e o coeficiente de variação experimental, determi 
nou-se um índice ( $\left.I^{\prime}\right)$, o qual nos dá uma indicação da variabilidade genética de um caráter, sem a influência da média geral do mesmo. Tal indice serviu muito bem como um outro processo alternativo, para indicar a contribuição genética para a expressão fenotípica dos caracteres. Concordando com os resulta dos apresentados anteriormente na Tabela 4 , os maiores indices se referem aos caracteres que apresentaram, proporcionalmente, maior variação genética e menor variação ambiental.

Determinaram-se tambēm, os coeficientes de : determinação genotípico ( $\left.H^{\prime}\right)$ para os seis caracteres analisados. $\mathrm{Na}$ Tabela 6 , são apresentados os valores dos indices (I') . e dos coeficientes de determinação genotípico ( $\left.H^{\prime}\right)$. Nota-se que os caracteres, número de vagens produzidas por plantas, compri mento médio dos internódios, nümero de ramificações primárias e peso da matéria verde, apresentaram um coeficiente (H') maior, enquanto os caracteres comprimento da ramificação primária e peso da matéria seca, apresentaram um coeficiente (H') menor. Possivelmente, para os caracteres que apresentaram maior coefi ciente ( $\left.H^{\prime}\right)$, os métodos de seleção mais simples podem ser apli cados com muita chance de sucesso. Pela Tabela 6, pode-se tam bém verificar a existência de uma concordância muito grande com os valores dos indices (I'), coeficiente (H') e os resulta dos apresentados na Tabela 4. 
Tabela 6. Valores correspondentes aos indices (I') e aos coefi cientes de determinação genotípico (H') para os caracteres estudados em $C$. pubescens.

Caracteres

$$
I^{\prime}=\frac{\mathrm{CV}_{\mathrm{g}} \%}{\mathrm{CV} \%} \quad \mathrm{H}^{\prime} \%
$$

Peso da matéria verde $(\mathrm{kg})$

0,525

61,13

Peso da matéria seca (kg)

0,466

55,42

No de ramificações primārias

0,584

67,19

Compr. da ramif. primária (m)

0,425

51,97

Compr. médio dos internódios (m)

0,694

74,36

No de vagens prod. por planta

0,940

84,12

A variância genética expressa em porcentagem da variância fenotípica, o coeficiente de determinação genotípico $\left(H^{\prime}\right)$ e o indice ( $\left.I^{\prime}\right)$ são procedimentos bastante simples, porém servem para dar uma idéia da determinação genética,para a expressão fenotípica dos caracteres, mostrando assim, uma importância prática para o melhoramento, orientando o melhorista na escolha dos métodos de seleção.

Os coeficientes de correlação fenotipica e ambiental, foram obtios através das análises de variância e covariância realizadas para os seis caracteres. os produtos médios obtidos da análise dá covariância entre estes caracteres, 
são apresentados nas Tabelas 7 e 8 a seguir.

Tabela 7. Resumo das análises da covariância com os respectivos produtos médios entre os pares de caracteres* analisados em $C$. pubescens.

\begin{tabular}{lrrcccc}
\hline & & & \multicolumn{4}{c}{ Produto médio } \\
\cline { 5 - 7 } Fontes de variação & GL & & P.Q & P.R & Q.R & X.Y \\
\hline Repetição & 5 & 0,0022 & $-0,0187$ & 0,0315 & 0,0356 \\
Populações & 20 & 0,0025 & $-0,1799$ & $-0,0076$ & 0,0894 \\
Erro exper. & 100 & 0,0001 & $-0,0056$ & $-0,0000$ & 0,0356 \\
\hline
\end{tabular}

\begin{tabular}{lrcccc}
\hline \multirow{2}{*}{ Fontes de variação } & GL & \multicolumn{4}{c}{ Produto médio } \\
\cline { 3 - 6 } & & X.Z & Z.Y & X.R & X.P \\
\hline Repetições & 5 & 0,1325 & 0,1107 & $-0,0184$ & $-0,0623$ \\
Populações & 20 & $-2,1645$ & 0,2240 & $-0,0199$ & 0,1278 \\
Erro exper. & 100 & 0,9557 & 0,2003 & $-0,0407$ & 0,0047 \\
\hline
\end{tabular}

* $\mathrm{X}=$ peso da matéria verde; $\mathrm{Y}=$ peso da matéria seca; $\mathrm{Z}=$ nümero de ramificações primárias; $\mathrm{P}$ = comprimento da ramificação primária; $Q=$ comprimento mēdio dos internódios e $\mathrm{R}=$ número de vagens por plantá. 
Tabela 8. Resumo das análises de covariância, com os respectivos produtos médios entre os caracteres* analisados em C. pubescens.

\begin{tabular}{|c|c|c|c|c|}
\hline \multirow{2}{*}{ Fontes de variação } & \multirow{2}{*}{ GI } & \multicolumn{3}{|c|}{ Produto médio } \\
\hline & & $\mathrm{Z} \cdot \mathrm{R}$ & $Z \cdot Q$ & $\mathrm{Z} . \mathrm{P}$ \\
\hline Repetições & 5 & 2,5020 & $-0,0694$ & 1,1093 \\
\hline Populações & 20 & $-2,3080$ & 0,0112 & 1,2300 \\
\hline Erro exper. & 100 & $-0,3360$ & 0,0088 & 0,1290 \\
\hline
\end{tabular}

\begin{tabular}{lrcccr} 
Fontesde variação & GL & \multicolumn{4}{c}{ Produto médio } \\
\cline { 3 - 6 } & & X.Q & Y.P & Y.Q & Y.R \\
Repetições & 5 & $-0,0016$ & $-0,0186$ & $-0,0002$ & $-0,0103$ \\
Populações & 20 & 0,0066 & 0,0375 & 0,0018 & 0,0062 \\
Erro exper. & 100 & 0,0004 & 0,0062 & 0,0001 & $-0,0104$ \\
\hline
\end{tabular}

* $\mathrm{X}$ = peso da matéria verde; $\mathrm{Y}=$ peso da matéria seca; $\mathrm{Z}=\mathrm{n} \overline{\mathrm{i}}-$ mero de ramificações primārias, $\mathrm{P}=$ comprimento da ramificação primäria; $Q=$ comprimento médio dos internödios e $\mathrm{R}=\mathrm{n} \underline{\underline{u}}$ mero de vagens por planta.

Dás análises da covariância isolou-se os componentes dos produtos médios, ou sejó, covariância genética entre populações ao nivel de médias de parcelas e a covariância do erro experimental, para tocios os casos. A covariância feno 
típica entre dois caracteres foi determinada, atravēs da soma da covariância genética entre populações, mais a covariância do erro experimental. Na Tabela 9 são apresentados os valores correspondentes a covariância genética entre populações ao nível de médias de parcelas, covariância do erro experimental e da covariância fenotípica entre os caracteres.

Tabela 9. Valoresobtidos para as covariâncias genéticas entre populações $\left(\operatorname{Cov}_{p}\right)$, covariância do erro experimental (Cov) e covariância fenotípica $\left(\operatorname{Cov}_{F}\right)$ entre caracteres* em C. pubescens.

\begin{tabular}{|c|c|c|c|}
\hline $\begin{array}{l}\text { Pares de } \\
\text { caracteres }\end{array}$ & $\mathrm{Cov}_{\mathrm{p}}$ & Cov & $\operatorname{Cov}_{F}$ \\
\hline$P \cdot Q$ & $3,91 \cdot 10^{-4}$ & $1,48.10^{-4}$ & $5,39 \cdot 10^{-4}$ \\
\hline$P \cdot R$ & $-309,00 \cdot 10^{-4}$ & $-56,10 \cdot 10^{-4}$ & $-365,10.10^{-4}$ \\
\hline$Q \cdot R$ & $-12,70.10^{-4}$ & $1,51.10^{-6}$ & $-12,68.10^{-4}$ \\
\hline$X . Y$ & $89,60 \cdot 10^{-4}$ & $356,00 \cdot 10^{-4}$ & $445,60 \cdot 10^{-4}$ \\
\hline$X . Z$ & $-5200,00 \cdot 10^{-4}$ & $9557,00 \cdot 10^{-4}$ & $4357,00 \cdot 10^{-4}$ \\
\hline Y.Z & $39,50 \cdot 10^{-4}$ & $2003,00.10^{-4}$ & $2042,50.10^{-4}$ \\
\hline $\mathrm{Z} \cdot \mathrm{Q}$ & $3,99.10^{-4}$ & $87,90 \cdot 10^{-4}$ & $91,89 \cdot 10^{-4}$ \\
\hline$X \cdot Q$ & $10,30 \cdot 10^{-4}$ & $4,48 \cdot 10^{-4}$ & $14,78 \cdot 10^{-4}$ \\
\hline Y.Q & $2,83.10^{-4}$ & $1,07.10^{-4}$ & $3,90 \cdot 10^{-4}$ \\
\hline$X . P$ & $205,00.10^{-4}$ & $47,10 \cdot 10^{-4}$ & $252,10 \cdot 10^{-4}$ \\
\hline$X \cdot R$ & $34,60.10^{-4}$ & $-407,00 \cdot 10^{-4}$ & $-372,00.10^{-4}$ \\
\hline$Y . P$ & $52,10.10^{-4}$ & $62,50.10^{-4}$ & $114,60.10^{-4}$ \\
\hline$Y \cdot R$ & $27,70 \cdot 10^{-4}$ & $-104,00 \cdot 10^{-4}$ & $-76,40.10^{-4}$ \\
\hline $\mathrm{Z} \cdot \mathrm{R}$ & $-3286,00 \cdot 10^{-4}$ & $-3360,00 \cdot 10^{-4}$ & $-6646,00 \cdot 10^{-4}$ \\
\hline $\mathrm{Z} \cdot \mathrm{P}$ & $1835,00 \cdot 10^{-4}$ & $1290,00 \cdot 10^{-L}$ & $3125,00-10^{-4}$ \\
\hline
\end{tabular}

$\star X=$ peso da matéria verde; $Y=$ peso da matéria seca; $Z$ = núme ro de ramificaçöes primárias; $\mathrm{P}=$ comprimento da ramificaçáprimária; $Q=$ comprimento médio dos inteinódios e $F=$ nümero de vagens por planta. 
Através das variâncias e covariâncias fenotípicas obtidas, foram determinados os coeficientes de correlação fenotipica entre todos os caracteres estudados. Os coeficientes de correlação fenotípica estão apresentados na Tabela 10.

Tabela 10. Coeficientes de correlação fenotípica entre os caracteres peso da matéria verde $(X)$, peso da matéria seca (Y), no de ramificações primārias ( $\mathrm{Z}$ ), comprimento da ramificação primária (P), comprimento médio dos internódios (Q) e ne de vagens por planta (R) em $C$. pubescens e a significância dos mesmos.

\begin{tabular}{|c|c|c|c|c|c|c|}
\hline Caracteres & $\mathrm{x}$ & $Y$ & $\mathrm{z}$ & $\mathrm{P}$ & $Q$ & $\mathrm{R}$ \\
\hline \multicolumn{7}{|l|}{$\mathrm{x}$} \\
\hline $\mathrm{Y}$ & $0,985 * *$ & & & & & \\
\hline Z & $0,201 *$ & $0,330 * *$ & & & & \\
\hline $\mathrm{P}$ & $0,236 * *$ & $0,375 * *$ & $0,214 * *$ & & & \\
\hline Q & $0,284 * *$ & $0,285 * *$ & $0,136^{\mathrm{ns}}$ & $0,151^{\text {ns }}$ & & \\
\hline $\mathrm{R}$ & $-0,149^{\mathrm{ns}}$ & $0,108^{\mathrm{ns}}$ & $0,194 *$ & $-0,217 * *$ & $-0,167^{\mathrm{ns}}$ & \\
\hline
\end{tabular}

* - significância ao nível de 5\% de probabilidade. ** - significâncía ao nîvel de Io de probabilidade. ns - não significância. 


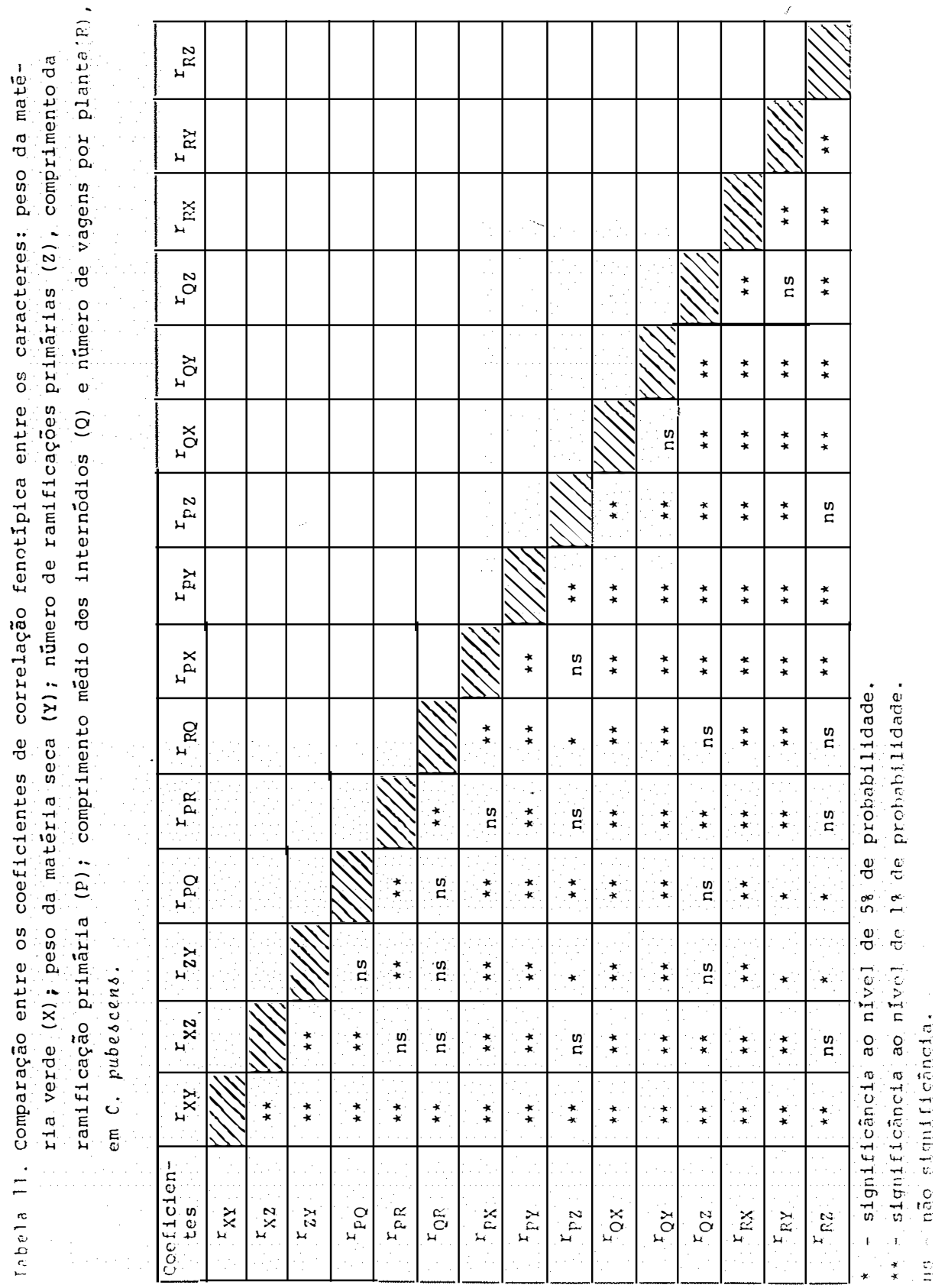


Pode-se observar na Tabela 10, que a maioria desses coeficientes são significativos aos níveis de 5 e 18 de probabilidade, indicando que os mesmos diferem de zero e que, os dois caracteres (variāveis) estão bem correlacionados. Para os casos onde não foi possível detectar significância, é porque os dois caracteres envolvidos apresentam pouca ou nenhu ma correlação entre eles.

Considerando os caracteres vegetativos $(X=$ peso da matéria verde, $Y=$ peso da matéria seca, $Z=$ número de ramificações primārias, $Q$ = comprimento médio dos internódios), pode-se observar na Tabela 10, que os mesmos apresentam pouca ou nenhuma correlação fenotípica com o caráter reprodutivo número de vagens produzidas por planta (R); sendo que entre os caracteres comprimento da ramificação primária (P) e o no de vagens produzidas por planta (R), existe uma correlação fenotí pica alta e negativa.

Esta pequena correlação fenotípica, que foi observada entre o caráter reprodutivo $(R=$ número de vagens produzidas por planta) e a maioria dos caracteres vegetativos e também a correlação negativa verificada entre este caráter reprodutivo e o comprimento da ramificação primāria (P), concor dam plenamente com a teoria da seleção $r$ e $k$ proposta em 1967, por Mac Arthur e Wilson (PIANKA, 1974). De acordo com essa teoria, uma planta que desloca mais energia para o desenvolvimento vegetativo produz pouca quantidade de flores, vagens e consequentemente pouca semente. Quando direciona mais energia 
para o desenvolvimento dos caracteres reprodutivos, os caracte res vegetativos desenvolvem menos. A teoria da seleção $r$ e k parece estar ligada com o ciclo vital das plantas. As plantas anuais geralmente adotam a estratégia-r, ou seja, - direciona maior parte da energia armazenada para o desenvolvimento de ca racteres ligados com as funções reprodutivas, enquanto que as plantas perenes, em virtude da competição que sofre no campo com outras espécies, durante toda a sua vida, geralmente adotam a estratégia-k, ou seja, direciona maior parte da energia armazenada, para o desenvolvimento dos caracteres vegetativos.

A Centrosema pubescens sendo uma planta perene, deve adotar, provavelmente, a estratégia-k, que permite a mesma, desenvolver mais vegetativamente e isto justifica os resul tados encontrados para as correlações fenotípicas entre o cará ter reprodutivo e os caracteres vegetativos na Tabela 10.

A Tabela 11, mostra que para a maioria dos casos os coeficientes de correlação fenotípica diferem um do outro e que somente poucos coeficientes não diferiram um do outro. Os coeficientes de maior magnitude indicam maior correla ção fenotípica.

O maior coeficiente de correlação fenotípica foi observado entre os caracteres peso da matéria verde $(X)$ e peso da matéria seca (Y). Este coeficiente difere significativamen te dos outros coeficientes e isto indica que esses caracteres 
apresentam uma correlação fenotípica maior do que os outros. Entre os caracteres comprimento da ramificação primária (P) e peso da matéria seca (Y) foi observado, também uma correlação fenotípica alta $(r=0,375)$. Este coeficiente difere significativamente dos outros com relação a correlação fenotípica entre eles.

o coeficiente de correlação fenotípica entre os caracteres comprimento médio dos internódios $(Q)$ e peso da matéria verde $(\mathrm{X})$ e b coeficiente entre os caracteres comprimento médio dos internódios (Q) e peso da matéria seca (Y) diferem também, significativamente dos outros, porém não existe diferença entre os mesmos quanto a correlação fenotípica.

Os coeficientes de correlação ambiental entre os caracteres, foram determinados através das variâncias e covariâncias do erro experimental. Na Tabela 12 estão apresentą dos os valores destes coeficientes, para os diversos casos. 
Tabela 12. Coeficientes de correlação ambiental entre os carac teres peso da matéria verde (X), peso da matéria se ca (Y), no de ramificações primárias ( $\mathrm{Z})$, comprimen to da ramificação primária (P), comprimento médio dos internódios (Q) e $\mathrm{n} \Phi$ de vagens por planta em $C$. pubescens e a significância dos mesmos.

\begin{tabular}{|c|c|c|c|c|c|c|}
\hline Caracteres & $\mathrm{x}$ & $\mathrm{Y}$ & $\mathrm{z}$ & $\mathrm{P}$ & $Q$ & $\mathrm{R}$ \\
\hline $\mathrm{x}$ & & & & & & \\
\hline $\mathrm{Y}$ & $0,976 * *$ & & & & & \\
\hline $\mathrm{z}$ & $0,573 * *$ & $0,413 * *$ & & & & \\
\hline $\mathrm{P}$ & $0,054^{\mathrm{ns}}$ & $0,244 * *$ & $0,111^{\mathrm{ns}}$ & & & \\
\hline$Q$ & $0,111^{\mathrm{ns}}$ & $0,095^{\mathrm{ns}}$ & 0,184 * & $0,040^{\mathrm{ns}}$ & & \\
\hline $\mathrm{R}$ & $-0,251 * *$ & $-0,221^{*}$ & $-0,156^{\mathrm{ns}}$ & $-0,049^{\mathrm{ns}}$ & $-0,003^{n s}$ & \\
\hline
\end{tabular}

Deve-se considerar que as correlações que se en contram na Tabela 10, são apenas fenotípicas e, por isso, essas associações entre os caracteres, podem estar muito mascara das pelos efeitos ambientais. Na Tabela 12, pode-se observar que em alguns casos esses coeficientes são significativos nos níveis de 1 e 5응 de probabilidade, indicando assim, que existe grande associação entre os caracteres, devido a efeitos ambien 
tais. Em alguns casos essa associação é muito grande, como se pode observar pelas magnitudes dos coeficientes.

A não significância de determinados coeficien tes de correlação ambiental, indica existência de pouca ou nenhuma associação entre os caracteres, devido a efeitos ambientais. Isto é bom para o melhoramento, porque, se existir uma correlação fenotípica entre esses caracteres, esta correlação será, provavelmente, devida a correlação genética existente en tre os mesmos.

Para os casos onde existe correlação fenotípica alta e correlação ambiental também alta, não se pode afirmar que tais caracteres se correlacionam geneticamente, como acontece com os caracteres peso da matéria verde (X) e peso da matéria $\operatorname{seca}(Y)$.

Nos casos, onde a correlação fenotípica entre dois caracteres é positiva, porém, tais caracteres apresentam correlações ambientais de maior magnitude, é possível que a as sociação devido a efeitos genēticos entre os caracteres considerados, não ocorra, ou ainda sejam correlacionados negativamente, como acontece entre os caracteres peso da matéria verde (X) e número de ramificações primárias (Z), nas Tabelas 10 e 12. Isto constitui um problema muito sério para o melhorista, porque se ele fizer seleção para melhorar o caráter peso da ma téria verde $(X)$, não terá condições de saber o que vai aconte- 
cer com o caráter número de ramificações primārias (Z). O mes mo problema acontece entre os caracteres peso da matéria seca (Y) e número de ramificações primárias e também entre o peso da matéria seca e o comprimento da ramificação primária.

Numa condição como a dos caracteres peso da matéria verde $(X)$ e comprimento da ramificação primária (P), os quais são positivamente correlacionados ao nível de $1 \%$ de probabilidade, porém, não existe correlação ambiental entre os mesmos, é possível, que a correlação fenotípica verificada, se ja principalmente devida a correlação genética existente entre esses caracteres. Esta situação também se verifica entre os caracteres número de ramificações primárias (Z) e comprimento da ramificação primária (P), comprimento médio dos internódios (Q) e peso da matéria verde (X) e entre o comprimento médio dos internódios (Q) e peso da matéria seca (Y) e ainda, possiveimente, entre os caracteres comprimento da ramificação primária (P) e peso da matéria seca (Y) que apresenta coeficiente corre lação ambiental menor que o coeficiente de correlação fenotípi ca. Estas situações são desejāveis para o melhorista, porque se ele fizer seleção sobre um caráter, terá condições de sâ ber o que irá acontecer com o outro, ou seja, se fizer seleção para melhorar o número de ramificações primárias, estará prova velmente, selecionando para melhorar o comprimento da ramifica ção primāria.

Uma situação muitas vezes indesejävel no melho- 
ramento de plantas, é a que ocorre entre os caracteres comprimento da ramificação primāria (P) e o número de vagens ( $R$ ), on de a correlação fenotípica é negativa e alta e a correlação am biental é nula. Neste caso, a correlação genética provavelmen te existe e também é negativa. Portanto, se for feita seleção para aumentar o comprimento da ramificação primāria, estaremos simultaneamente selecionando para diminuir o número de vagens na planta.

Nas Tabelas 13 e 14 estão apresentadas as médias do carāter em cada população, em ordem decrescente " de grandeza, bem como, a média geral de cada caráter entre as 21 populações de C. pubescens.

E sabido que uma boa planta forrageira se carac teriza, entre outras coisas, por apresentar grande produção de massa verde e uma boa produção de sementes para sua reprodução e propagação. Isto vai contra a téoria da seleção $r$ e $k$, porque, segundo esta, de um modo geral, é difícil encontrar uma planta que produza muita massa verde e que produza também, mui ta semente.

Através de uma análise, considerando apenas a média do carāter na população e a média geral do carāter pode-se avaliar rapidamente o comportamento médio de algumas populações.

Considerando os caracteres vegetativos (X - pe- 
so da matéria verde, Y - peso da matéria seca, Z - no de rami-ficações primārias, P - compr. da ramificação primāria e Q compr. médio dos internódios), as populações que apresentaram valor médio, superior à média geral para um determinado caráter, geralmente mostraram o mesmo comportamento para os demais. Por outro lado, a classificação de um caráter vegetativo, discorda da classificação, quando se considera seu caráter reprodutivo, na maioria dos casos. Isto concorda com as corre lações fenotipicas mostradas anteriormente.

Pode-se então verificar, que as populações que preenchem melhor os requisitos de uma boa planta forrageira, são as seguintes: $2($ IZ-246): $6($ EEI-35/76), $7($ IZ-724), 11 (IZ-243), 15 (IZ-345), 16 (cultivar Deodoro) e a 21 (IZ-245), Todas estas populações apresentaram grande produção de massa verde e boa produção de vagens. 
Tabela 13. Médias obtidas para peso da matéria verde (X), pesoda matéria seca (Y) e nūmero de ramificações primárias por planta ( $\mathrm{Z})$, colocadas em ordem decrescente de grandeza. Centrosema pubescens. Piracicaba-SP, 1979.

\begin{tabular}{|c|c|c|c|c|c|}
\hline \multicolumn{2}{|c|}{$\mathrm{X}$} & \multicolumn{2}{|c|}{$\mathrm{Y}$} & \multicolumn{2}{|r|}{2} \\
\hline Pop. & $(\mathrm{kg})$ & Pop. & $(\mathrm{kg})$ & Pop. & (unidades) \\
\hline 2 & 1,458 & 15 & 0,419 & 21 & 31,386 \\
\hline 7 & 1,439 & 6 & 0,412 & 4 & 29,719 \\
\hline 12 & 1,414 & 3 & 0,408 & 15 & 28,719 \\
\hline 15 & 1,409 & 7 & 0,408 & 8 & 26,386 \\
\hline 6 & 1,375 & 12 & 0,399 & 3 & 26,108 \\
\hline 16 & 1,279 & 16 & 0,370 & 13 & 25,884 \\
\hline 10 & 1,262 & 10 & 0,352 & 12 & 25,829 \\
\hline 4 & 1,207 & 4 & 0,343 & 19 & 23,551 \\
\hline 8 & 1,180 & 8 & 0,334 & 11 & 23,273 \\
\hline 13 & 1,122 & 13 & 0,322 & 10 & 23,218 \\
\hline 21 & 1,106 & 18 & 0,321 & 9 & 23,208 \\
\hline 18 & 1,090 & 11 & 0,320 & 17 & 22,884 \\
\hline 17 & 1,083 & 17 & 0,319 & 1,6 & 22,718 \\
\hline 11 & 1,072 & 1 & 0,313 & 7 & 22,609 \\
\hline 1 & 1,050 & 21 & 0,302 & 16 & 21,803 \\
\hline 3 & 1,020 & 3 & 0,288 & 14 & 21,384 \\
\hline 5 & 0,926 & 19 & 0,278 & 18 & 20,941 \\
\hline 19 & 0,920 & 9 & $0,2.75$ & 20 & 20,941 \\
\hline 9 & 0,896 & 5 & 0,274 & 1 & 20,496 \\
\hline 20 & 0,818 & 20 & 0,236 & 2 & 19,163 \\
\hline 14 & 0,541 & 14 & 0,159 & 5 & 18,831 \\
\hline $\begin{array}{l}\text { média } \\
\text { geral }\end{array}$ & 1,127 & & 0,327 & & 23,764 \\
\hline
\end{tabular}


:56:

Tabela 14. Médias obtidas para comprimento da ramificação primāria (P), comprimento médio dos internódios (Q) e número de vagens produzidas por planta (R), ordenadas em ordem decrescente de grandeza. Centrosema pubescens. Piracicaba-SP, 1979.

\begin{tabular}{|c|c|c|c|c|c|}
\hline \multicolumn{2}{|c|}{$\mathrm{P}$} & \multicolumn{2}{|c|}{$Q$} & \multicolumn{2}{|c|}{$\mathrm{R}$} \\
\hline Pop. & (metros) & Pop. & (metros) & Pop. & (unidades) \\
\hline 16 & 2,309 & 2 & 0,133 & 18 & 223,55 \\
\hline 12 & 2,284 & 16 & 0,127 & 9 & 110,944 \\
\hline 13 & 2,273 & 11 & 0,121 & 6 & 81,222 \\
\hline 4 & 2,271 & 17 & 0,121 & 1 & 77,294 \\
\hline 21 & 2,253 & 21 & 0,120 & 11 & 74,055 \\
\hline 10 & 2,248 & 4 & 0,119 & 16 & 73,444 \\
\hline 1 & 2,198 & 10 & 0,118 & 20 & 64,352 \\
\hline 7 & 2,196 & 7 & 0,118 & 2 & 52,277 \\
\hline 2 & 2,146 & 15 & 0,117 & 7 & 50,277 \\
\hline 15 & 2,138 & 19 & 0,117 & 3 & 34,882 \\
\hline 6 & 2,124 & 12 & 0,116 & 21 & 34,705 \\
\hline 3 & 2,101 & 6 & 0,115 & 10 & 30,111 \\
\hline 17 & 2,061 & 13 & 0,113 & 15 & 27,882 \\
\hline 8 & 2,044 & 3 & 0,113 & 19 & 26,882 \\
\hline 11 & 2,028 & 20 & 0,110 & 5 & 22,333 \\
\hline 19 & 2,026 & 1 & 0,110 & 8 & 20,823 \\
\hline 20 & 2,014 & 8 & 0,109 & 12 & 15,705 \\
\hline 5 & 2,004 & 5 & 0,106 & 4 & 13,888 \\
\hline 14 & 1,891 & 14 & 0,106 & 17 & 10,277 \\
\hline 9 & 1,834 & 9 & $0,0,97$ & 14 & 7,444 \\
\hline 18 & 1,829 & 18 & 0,089 & 13 & 0,833 \\
\hline $\begin{array}{l}\text { média } \\
\text { geral }\end{array}$ & 2,108 & & 0,115 & & 50,151 \\
\hline
\end{tabular}


7. CONCLUSOEES

O presente trabalho possibilitou obter as seguintes conclusões, em relação as 21 populações de C.pubescens Benth estudadas:

a. Existe grande variabilidade genética entre as populações;

b. Os caracteres, número de vagens produzidas por planta, comprimento médio dos internódios, número de ramificações primárias e peso da matéria verde, exibiram maior variabilidade genética, em relação aos demais;

c. O indice (I') e o coeficiente de determinação genotípico (H'), foram bons indicadores da magnitude da variabilidade genética de cada caráter avaliado, existindo tam bém entre ambos uma concordância muito grande;

d. Respostas räpidas devem ser obtidas na sele- 
ção para os caracteres que apresentaram maiores coeficientes de determinação genotípico: número de vagens produzidas por planta, comprimento médio dos internódios, nümero de ramificações primārias e peso da matérìa verde.

e. O maior coeficiente de correlação fenotípica encontrado, foi entre os caracteres peso da matéria verde e pe so da matéria seca;

f. A maioria dos caracteres vegetativos apresen taram pouca ou nenhuma correlação fenotípica com o número de vagens;

g. Entre os caracteres comprimento da ramificação primária e o número de vagens por planta a correlação feno típica é negativa;

h. Maiores dificuldades são esperadas, quando a seleção é praticada em caracteres com altas correlações fenotí picas e ambientais: peso da matéria verde e peso da matéria se ca, peso da matéria seca e comprimento da ramificação primária, número de ramificações primárias e peso da matéria verde e entre peso da matéría seca e o número de ramificações primárias;

i. Maiores facilidades são esperadas; quando a seleção é praticada em caracteres com correlações fenotípicas altas e correlações ambientais pequenas ou nulas: número de ramificações primárias e peso da matéria verde, comprimento mé 
dio dos internódios e peso da matéria verde e entre comprimento da ramificação primária e o número de ramificações primárias;

j. As populações $2($ IZ-246), 6 (EEI-35/76), 7 $(I Z-724), 11(I Z-243), 15(I Z-345), 2 I(I Z-245)$ e a 16 (cultivar Deodoro), mostraram ser as mais promissoras, devido apresentarem desejāveis desenvolvimento vegetativo e produção de vagens. 


\section{SUMMARY}

This work was carried out at the "Instituto de Genētica", ESALQ, USP, Piracicaba, SP, in 1979, to evaluate the variability and the phenotypical and environmental correlations between agronomic characteres in twenty one populations of Centrosema pubescens, a Brazilian native perennial legume.

A randomized block design with six replications, twenty one treatments and six plants per plot, was utilized. The characters analysed were: green matter production, dry matter production, number of main stems, length of main stem, mean length of internodes, and number of pods per plant.

The results obtained demonstrated that high genetic variability exists for number of pods per plant, mean length of internodes, number of main stems and green matter production. It was verified that most of the characters are well correlated phenotypicaly and that between some characters 
the environmental correlation is high.

In the conditions of the present experiment, populations EEI-35/76, IZ-724, IZ-345, IZ-245, IZ-246, IZ-243 and the $\mathrm{cv}$. Deodoro are the most promising populations, because they have a good vegetative growth and high pod produtions. 


\section{LITERATURA CITADA}

ALBA, J. de, 1963. Alimentacion del ganado en América Latina. la. Edicion México. Editorial Fournier, S.A. Arquitectura 29, Copilco - Universidad, México 20, 336 p.

ALCÂNTARA, P.B. e G. BUFARAH, 1979. Plantas forrageiras (Gramineas \& Reguminosas). São Paulo, Nobel 150 p.

ALCÂNTARA, P.B., V. de B.G. ALCÂNTARA, J.M.M. SIGRIST e F. S. PULZ, 1977. Caracterização de cinco introdução de centrose ma pubescens Benth. Bor. Industr. anim., Nova Odessa, São Paulo, 34(1):103-111.

ANDREW, C.S. e M.F. ROBINS, 1969. The effect of phosphorous on the growth and chemical composition of some tropical pasture. II - Nitrogen, Calcium, Magnesium, Potassium and Sodium contents. Austr. J. Agric. Research, Victoria, 20: $675: 685$. 
ARONOVICH, S., A. SERPA e H. RIBEIRO, 1970. Effect of nitrogen fertilizer and legume upon beef production on pangolagrass pasture. Proc. XI Int. Grassid. Congr., Austrália, p. 796-800.

BARBOSA-FEVEREIRO, V.P., 1977. Centrosema (A.P. de CANDOLLE) Benthan do Brasil - Leguminosae - Faboideae. Rodriguésia, Rio de Janeiro, p. 159-219.

BOGDAN, A.V., 1977. Tropical pasture and fodder plants (grasses and Zegumes). Longman, London and New York. $475 \mathrm{p}$.

CARVALHO, S.R. de, S. ARONOVICH e P.F.I. FARIA, 1975. Estabecimento de leguminosas forrageiras tropicais em consorciação com gramíneas na zona leiteira do Vale do Paraíba Fluminense. Rev. Soc. Bras. Zootec., $\underline{4}(1): 12-18$.

CESNICK, R., 1972. Estudo da herdabilidade de alguns caracteres em cana-de-açūcar. Piracicaba, ESALQ/USP/IGEN, 78 p. (Tese doutoramento).

CHOU, CHANG-HUNG, M.T. YEH, C.C. LIANG e C. HUANG, 1977. Quantity and composition of amino acids of leaf protein concentrates in five tropical leguminous plants. Bot.Bull. Acad. Sinica, Taiwan, 18:101-108. 
CLEMENTS, R.J., 1977. Agronomic variation in Centrosema virg $\underline{i}$ nianum in relation to it's use as a subtropical pasture plants. Austr. J. of Exper. Agric. and Anim. Husb., Victoria, $17(86): 435-444$.

CORREA, M.P., 1926. Dicionärio das plantas üteis do Brasiz e das exöticas cultivadas. Rio de Janeiro, Minist. da Agri cultura, $4 \mathrm{v}$.

FALCONER, D.S., 1964. Introduction to quantitative genetics. 3a. imp., New York, The Ronald Press Company. 365 p.

FURTADO, X.C., A. dOS R. CONDE, J.M. SOBRINHO e A. MENDONÇA, 1977a. Efeito da consorciação de leguminosas com o capim colonião (Panicum maximum). Relatório Técnico, EMGOPA, Goi às, $1: 48-49$.

FURTADO, X.C., A. dOS R. CONDE, J.M.M: SOBRINHO e A. MENDONÇA, 1977b. Efeito da consorciação de leguminosas com o capim jaraguá (Hyparrhenia rufa). ReZatório Técnico, EMGOPA, Goi às, I: $50-51$.

FURTADO, X.C., A. dOs R. CONDE, J.M.M. SOBRINHO è A. MENDONÇA, 1977c. Efeito da consorciação de leguminosas com o capim elefante (Pennisetum purpureum). Relatörio Técnico, EMGOPA, Goiās, $1: 52-53$. 
FURTADO, X.C., A. dOs R. CONDE, J.M.M. SOBRINHO e A, MENDONÇA, 1977d. Efeito da consorciação de leguminosas com o capim brachiária (Brachiaria decumbehs). Relatório Técnico, EMGOPA, Goiás, 1: 62-63.

HORREL, C.R. E P.N. NEWHOUSE, 1965. Yields of sown pasture in Uganda, as influenced by legumes and by fertilizers. In: Anais d̀o IX Congr. de Pastagens, são Paulo, 2:1133-1136.

HUTTON, E.M., 1960. Flowering and pollination in Indigofera spicata, Phaseolus lathyroides, Desmodium uncinatum and some other tropical pasture legumes. Emp. J.Exper. Agric., Oxford, $28: 235-243$.

HYMOWITZ, T., 1971. Collection and evaluation of tropical and subtropical brazilian forrages. Tropical Agriculture, Trinidad, $48(4): 309-315$.

JONES, M.B., J. QUAGHATO e I.M.M. FREITAS, 1970. Respostas de Alfafa e algumas leguminosas tropicais a aplicação de nutrientes minerais em 3 solos de campo cerrado. Pesq. Agrop. Bras., Rio de Janeiro, 5:209-214.

KANNEGIETER, A., 1965. The cultivation of grasses and legumes in the forest zone of Ghana. In: Anais do IX Congr. Int. de Pastagens, são Paulo, I:313-318.

KEMPTHORNE, O., 1957. An Introduction to Genetics Statistics. New York, John Wiley \& Sons, Inc., 545 p. 
KEMPTHORNE, O., 1973. The Design and Analyses of Experiments. 6a. Edition, New York, Robert E. Krieger Publishing Co. Inc., $631 \mathrm{p}$.

MATTOS, H.B., 1973. Características agronômicas de algumas le guminosas forrageiras de clima tropical. In: Curso de PósGraduag̃ão de Nutrição Animal e Pastagens, Disciplina: Manejo de pastagens. Piracicaba, são Paulo, ÉSALQ, 18 folhas.

MATTOS; H.B., 1974. Leguminosas forrageiras. In: Assistência Nestî́ aos produtores de leite. Io Encontro de atualização em pastagens. São Paulo, 2 (1): 71-99.

MATTOS, H.B., J.V.S. PEDREIRA e L. MELOTTI, 1978. Efeito do pastejo na persistência de algumas leguminosas de clima tro pical. Bol. Indust. Anim., Nova Odessa, São Paulo, $35(1)$ : $81-87$.

MONTEIRO, F.A., 1977. Nutrição mineral da centrosema pubescens Benth. Zootecnia, Nova Odessa, São Paulo, 15(1): 37$-56$.

NEME, A.M. e J.P. NERY, 1965. Influência de adubos minerais e do calcáreo na produção e composição de leguminosas forra geiras perenes. In: Anais do IX Congr. Int. de Pastagens. São Paulo, 1: $1: 665-670$. 
NOGALLES, P., 1955. Ensayos preliminares de asociaciones entre gramineas y leguminosas tropicales forrajeras. Agronomia Tropical. Maraçay, $\underline{5}(4): 227-237$.

NORRIS, D.O., 1972. Leguminous plants in tropical pastures. Trop. Grasszd., Brisdane, $\underline{6}(3): 159-170$.

OTERO, J.R., 1961. Informações sobre algumas plantas forragei ras. 2a. edição, Rio de Janeiro, Brasil. 334 p.

PEDREIRA, J.V.S., H.B. MATTOS, L. MELOTTI e H.M. de COSTA JUNIOR, 1975. Estimativa da capacidade suporte de capins con sorciados com leguminosas. Bol. Indust. Anim., Nova Odes sa, São Paulo, $\underline{32}(2): 281-292$.

PEDROSA, A.C., G.L. ROCHA, 1977. Efeitos da profundidade de semeadura, adubação e compactação, na emergência e estabele cimento de Centrosema (Centrosema pubescens Benth, linhagem IPEACS-5.1). Bol. Indust. Anim., Nova Odessa, São Paulo, 34 (2) : 263-299.

PEIXOTO, A.M., C.L. MORAIS e A.O. PRÓSPERO, 1965. Contribuição ao estudo da composição química e digestibilidade do feno de soja perena (Glycine javanica). In: Anais do IX Congr. Int. de Pastagens. São Paulo, 2: 791-795. 
PETIT, P.G., 1968. Aceptabilidad relativa de algunas legumino sas tropicales y métodos para evaluarla. Turrialba, 18(4): 439-4 41.

PHIPPS, R.H., 1973. Methods of increasing the germination percentage of some tropical legumes. Tropical Agriculture, Trinidad, $50(4): 291-296$.

PIANKA, E.R., 1974. Ev>lutionary Ecology. New York, Harper \& Row, publishers, $356 \mathrm{p}$.

REYES, B., 1955. The digestibility of Centrosema pubescens and Pueraria javanica. The Philippine Agriculturist, Los Bãnos, $39(1): 27-29$.

ROCHA, G.L. e S. ARONOVICH, 1972. Informe regional sobre problemas recentes de desenvolvimento no campo dos pastos e plantas forrageiras. Zootecnia, Nova Odessa, São Paulo, 10: $15-62$.

SARTINI, H.J.; M. SANTAMARIA, A.J. LOURENÇO, E.L. CAIELLI e G.I. da ROCHA, 1975. Ensaio de pastejo usando lotação fixa em consorciação entre capim gordura (Melinis minutiflora) e Centrosema pubescens. Zootecnia, Nova Odessa, são Paulo, $\underline{13}(4): 219-228$. 
SERPA, A., 1965. Melhoramento da Centros ema pubescens Benth, I - obtenção de variedades de sementes permeáveis. In: Anais do IX Congr. Int. de Pastagens. são Paulo, 1:171-174.

SERPA, A., 1974a. Viabilidade de alguns fatores que afetam a produção de sementes em Centrosema pubescens. Pesq. Agrop. Bras., Série Zootecnia, Rio de Janeiro, $9: 39-44$.

SERPA, A., 1974b. Novas perspectivas no melhoramento genético de Centrosema sp. In: Anais da XI Reunião da Soc. Bras. de Zootecnia. p. 224-225.

SERPA, A., 1977. Hibridação interespecífica entre centrosema pubescens e Centrosema virginianum. Pesq. Agrop. Bras., Rio de Janeiro, 12:35-40.

SOUTO, S.M., C.R. IIMA E E.D. de Lucas, 1975. Palatabilidade de leguminosas forrageiras tropicais. Pesq. Agrop. Bras., Série Zootecnia. Rio de Janeiro, 10:7-11.

SOUTO, S.M. e J. DOBEREINER, 1969. Toxidez do Manganês em leguminosas forrageiras tropicais. Pesq. Agrop. Bras., Rio deJaneiro, $4: 129-138$.

STEEL, R.G.D. and J.H. TORRIE, 1960. Principles and Procedures of Statistics. New York, Mv Graw-Hill. Book Company, Inc., $481 \mathrm{p}$. 
STOBBS, T.H., 1965. Beef productions from Uganda pasture containing Stylosanthes gracilis e Centrosema pubescens. In: Anais do IX Congr. Int. de Pastagens. São Paulo, 2: $939-942$.

TEITZEL, J.K. e R.I. BURT, 1976. Centrosema pubescens in Austrália. Trop. Grasszd., Brisdane, $10(1): 5-12$.

TOSI, H., V.P. de FARIA, A.C. SILVEIRA e R.L. PEREIRA, 1975. Avaliação de leguminosas forrageiras de origem tropical como plantas para ensilagem. Pesq. Agrop. Bras., Série Zootecnia, Rio de Janeiro, 10:19-22.

VASCONCELOS, C.N., 1972. Estudo do valor nutritivo e produção de cinco leguminosas tropicais na Zona da Mata de Minas Gerais. Viçosa, 39 p. (Dissertação - U.F.V.).

VENCOVSKY, R., 1978. Herança Quantitativa. In: Paterniani, E. Coord., Melhoramento e produsão de milho no Brasil. Piraci caba, ESALQ, p. 192-195.

VERBOOM, W.C., 1965. Legumes in Zambia. Tropical Agriculture, London, $42: 229-242$.

WENER, J.C. e H.B. MATTOS, 1972. Estudos de nutrição de Centrosema pubescens Benth. Bol. Industr. Anim., Nova Odessa, são Paulo, 29:375-39l. 
WILSON, A.S.B. e T.J. LANSBURY, 1958. Centrosema pubescens: Ground cover and forrage crop in cleared rain forest in Ghana. Emp. J. of Exper. Agric., Oxford, 26 (104):351-356. WHYTE, R.O., G. NILSSON-LEISSNER E H.C. TRUMBLE, 1955. Las Ze guminosas en la agricultura. Iuguslávia, FAO: Estudios agropecuários, n\& 21, 2a. imp., 405 p.

ZERPA, H. e H. VILLALOBOS, 1953. Asociaciones de gramíneas y. de leguminosas tropicales. Agronomia Tropical, Maracay, $\underline{3}$ (2) $: 123-128$. 